\title{
Considerations over the Italian road bridge infrastructure safety after the Polcevera viaduct collapse: past errors and future perspectives
}

\author{
Fabio Bazzucchi, Luciana Restuccia, Giuseppe Andrea Ferro \\ Politecnico di Torino, Turin, Italy \\ fabio.bazzucchi@polito.it, bttps://orcid.org/0000-0002-2624-6944 \\ luciana.restuccia@polito.it, bttps://orcid.org/0000-0002-6999-0466 \\ ferro@polito.it, bttps://orcid.org/0000-0002-0622-4203
}

\begin{abstract}
In the last four years, Italy experienced the collapse of five road bridge: Petrulla viaduct (2014), Annone (2016) and Ancona (2017) overpasses, Fossano viaduct (2017) and Polcevera (2018) bridge.

Although for deeply different reasons, the collapses occurred can all been gathered into the same common cause: the (lack of) knowledge of the effective structural condition, a serious problem that affects existing constructions.

As it will be shown in the paper, different problems such as missing of the asbuilt designs, an appropriate construction and movement precautions, a heavy vehicle checking, and a material decay monitoring can nevertheless be addressed as an inadequate knowledge of what is happening to/in the structure.

In the first section, the paper will report a short description of the failures for the five bridges, while in the second part a main set of problems involved in bridge safety and maintenance will be discussed. Finally, in the third part, a review on innovative and peculiar investigation and monitoring techniques will be illustrated. The collected results can shed new light on future perspectives for the Civil Engineering sector, sector that has to be ready for facing the challenges of preservation, restoration and/or replacement of the existing infrastructural constructions, worldwide.
\end{abstract}

KEYWORDS. Bridge collapse; Existing infrastructural constructions; Prestressed concrete failure; Bridge robustness; Innovative monitoring.
OPEN ACCESS

Citation: Bazzucchi, F., Restuccia, L. Ferro, G. A., Considerations over the Italian road bridge infrastructure safety after the Polcevera viaduct collapse: past errors and future perspectives, Frattura ed Integrità Strutturale, 46 (2018) 400-421.

Received: 28.08 .2018

Accepted: 27.09 .2018

Published: 01.10 .2018

Copyright: (C) 2018 This is an open access article under the terms of the CC-BY 4.0, which permits unrestricted use, distribution, and reproduction in any medium, provided the original author and source are credited.

\section{INTRODUCTION}

he Italian infrastructural patrimony, constituted by a conspicuous number of bridges, viaducts and overpasses necessary for the orographic of the territory and for the high urban density, is strongly fragile as it is by now dated and highly vulnerable. This fragility has dramatically highlighted in the last 4 years: there have been several collapses of bridges, viaducts and overpasses, which have wiped out lives, divided cities and heavily influenced mobility. 
This requires, especially in relation to recent events, a particular attention to the evaluation of existing infrastructures and to the planning of improvement and/or modification works. In particular, attention must be focused on the need to assess the degradation and estimation of the residual capacity of the structures in operational conditions.

The road infrastructures are very vulnerable, as they are afflicted by design (structural and technological) deficiencies essentially linked to the construction period, the applied technologies and the used materials together with, especially in the last years, to a lack of appropriate maintenance. Most of bridges and viaducts in Italy were built between the '50s and '60s, when the economic boom generated unlimited confidence in the use of concrete as a durable material for eternity. Moreover, the majority of these structures of the Italian road network have been realized through the technology - not yet mature at the time - of the prestressed reinforced concrete, hardly compatible, with the actual concepts of reliability and control. These structures are difficult to analyze because they do not have what is today defined as a plastic reserve: in the moments before the collapse, in general, there are no evidence of structural failure. This lack of ductility can not be considered as a design error. It would be more appropriate to highlight that in the sixties there were two fundamental factors that led to this situation:

- 1. there was no awareness that reinforced concrete could have such a short life and could suffer attacks and deterioration due to atmospheric and/or environmental agents.

- 2. there were no automatic calculation tools, therefore, where possible, statically determined schemes were preferred, much simpler to calculate. It was even said that they had to be preferred to the undetermined ones because they were adaptable to temperature variations and constraint settlements.

In reality, as it will be showed in the next, also most recent realizations (Fossano viaduct) suffered not for this immature technology, rather than an excessive confidence with the technology. It can be affirmed without any doubt that prestressed concrete structures need a redundancy in control during the realization phases.

Therefore, the main purpose of this work is to analyze the possible critical issues related to the structural safety of Italian road infrastructures in order to stimulate new efforts to be put in novel investigation methods, especially for a large-scale diagnosis, and strategic management. In particular, Petrulla viaduct (2014), Annone (2016) and Ancona (2017) overpasses, Fossano viaduct (2017) and Polcevera (2018) bridge will be briefly discussed to highlight the differences in terms of collapse causes which are a clear example of how much the Italian infrastructural system needs attention.

Another purpose is to stimulate the sensitivity of civil engineers who are called to face the great challenge of "knowing how to read" the existing buildings, establishing a connection between the past (full understanding of the project, detailed analysis, etc.) and the future, through the use of innovative diagnostic techniques. To do so, investments must bring nourishment to a sector, that did not have important technological evolutions in the recent years. Moreover this topic does not attract particularly the interest of the scientific world for a long period and just for that has large margin of growth, and, at the same time, desperate need of innovative technologies. It is also time to learn from our past errors and use them as background to define the requirements of a new cultural paradigm.

\section{CRITICAL ISSUES EMERGED IN THE LATEST COLLAPSES OF ROAD BRIDGE INFRASTRUCTURES}

\section{Petrulla viaduct: construction and durability}

7 he Petrulla viaduct is situated along the S.S. 626 "Valle del Salso", at km 4+500, in Sicily. The viaduct consists in a series of 12 simply supported beams, each of them with a $40 \mathrm{~m}$ span (Fig. 1(a)). On July 7, 2014, one span collapsed, injuring 4 persons. The breakage occurred in mid-span circa, and then, shear failure occurred where the deck impacted ground (Fig. 1(b)). The deck, $11.30 \mathrm{~m}$ wide, was made of 4 precast and prestressed concrete I-beams equally spaced by $2.850 \mathrm{~m}$. Five transverse beams realized the girder that supported the pavement slab (Fig. 1(c)). The investigation, conducted after the collapse, evidenced an exceeding state of material decay for the steel components: diffused oxidation in the prestressing cables, severe corrosions of the metallic sheathing and large absence of the protective grout inside the cables (Fig. 2(a), Fig. 2(b)). Since the bridge was built in the mid-80s, this degradation pattern was not compatible with 30 years of service life, especially because the concrete exhibited good signs preservation (Fig. $2(\mathrm{c}))$. The investigations have evidenced several construction flaws, in particular related to finishing operations of the prestressing. The grout injection was superficially carried out and the vent pipes were not accurately sealed (Fig. 2(d)). Under these circumstances, humidity found a preferential way into the cables, and its continuous content variation generated an aggressive environment for steel oxidation. Other additional deficiencies for this particular degradation scenario were addressed to:

- not sufficient cover due to malposition of the prestressing cables;

- not adequate workability and fluidity of the concrete; 
- inadequate waterproofing covering of the joints.

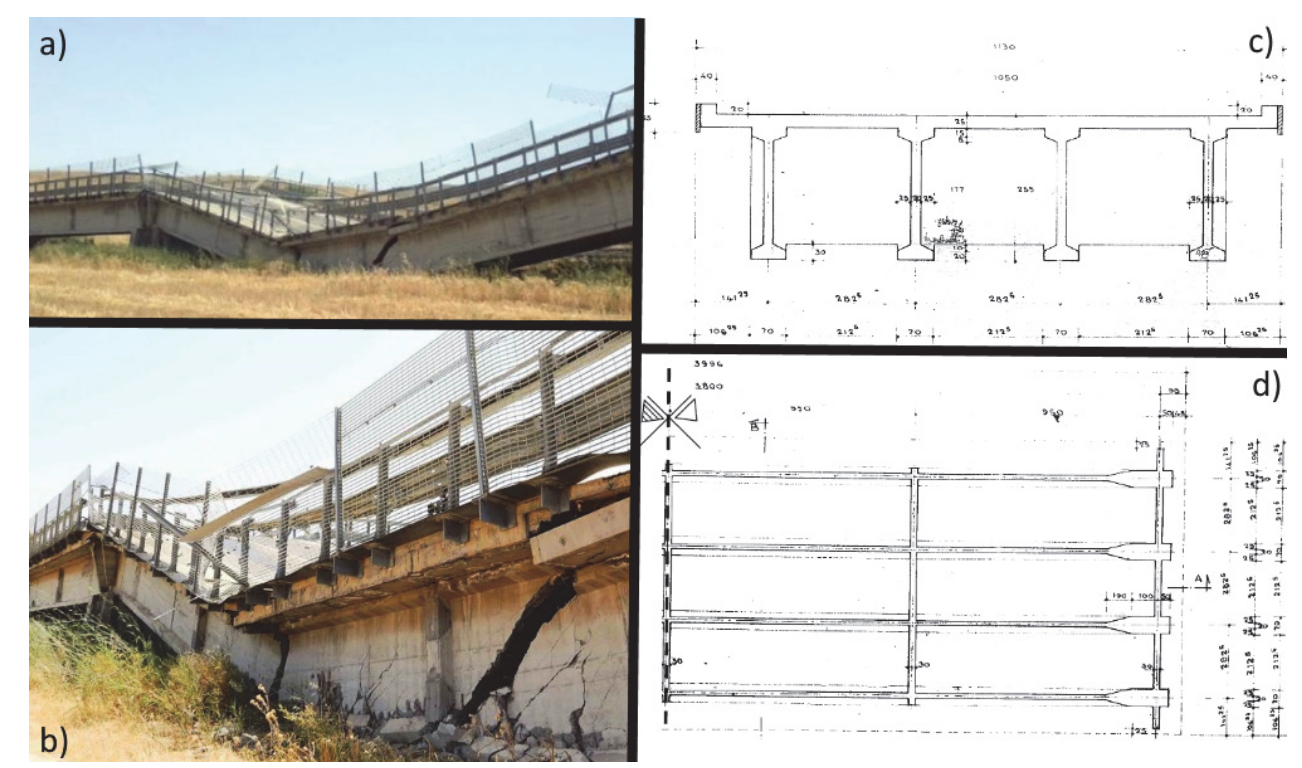

Figure 1: Overview of the Petrulla viaduct (a); collapsed structure (b); original design of the deck (c,d).
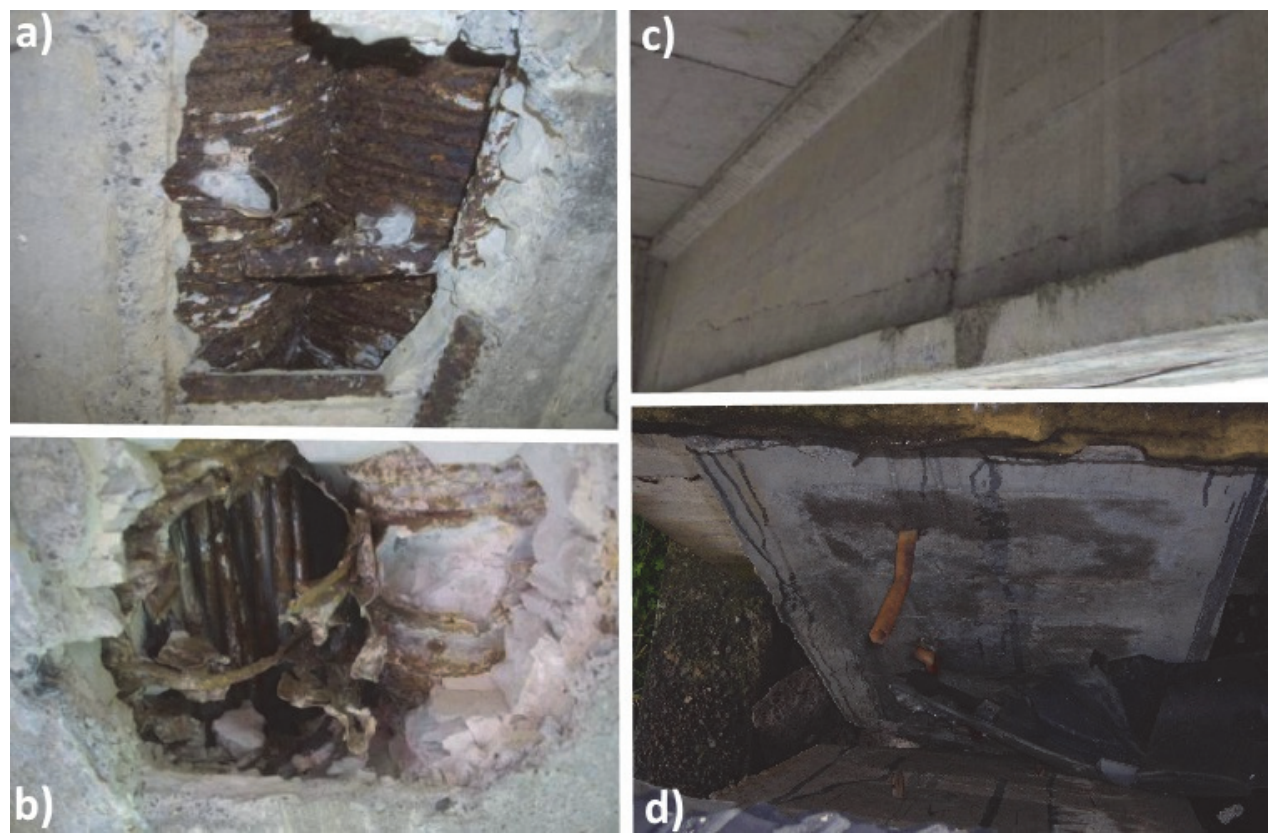

Figure 2: Steel components corrosion, strands (a), metallic sheathing (b); concrete condition (c); unsealed vent pipes (d).

A visual inspection campaign was carried out for all the others remaining beams that constituted the Petrulla viaduct. Four level of damage degree were defined, from no noticeable damage (green) to exposed prestressing cables with visible signs of oxidation (red). In Fig. 3(a), the visual inspection location with its relative degree of damage for the bridge $\mathrm{n} .2$ has been reported. In Fig. 3(b), results for the entire viaduct have been summarized. It is worth to note that, even if less than 7\% of the cases had a high degree of damage (blue and red), they represented 8 different visual inspections, which meant 8 possible beams with no active prestressing forces. This viaduct has been object of reparation and after four years has become operative again. It is reasonable to say that the investigation, repair, and public costs due to the inoperable structure are significantly higher than the ones associated with careful construction procedures. The adopted safety solutions are discussed in the next section (par 6). 
a)

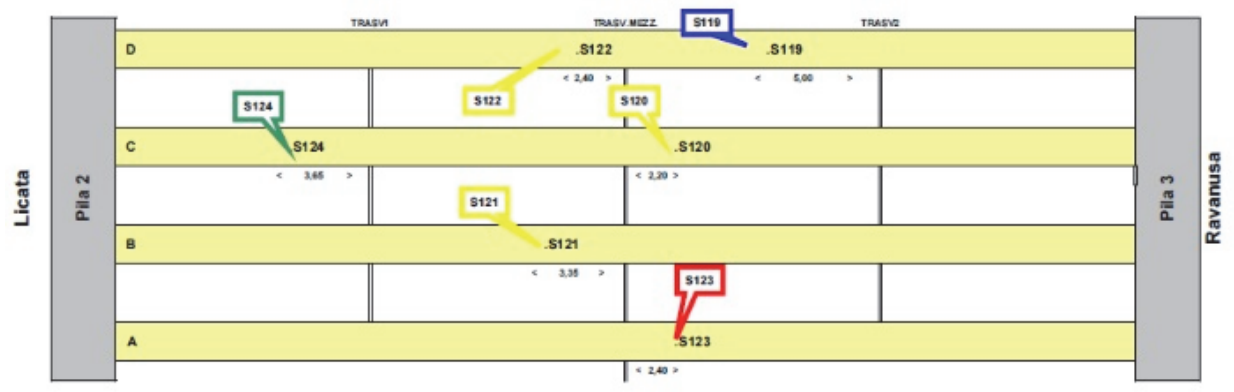

b)

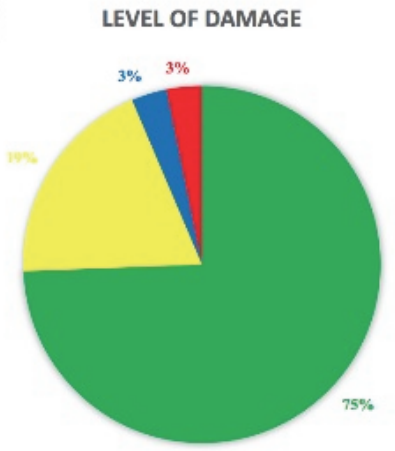

Figure 3: Example of the deck visual inspections (a); damage degree results survey (b).

\section{Annone overpass: maintenance design and load checking}

The collapse of the Annone overpass, Lecco, at km 42.000 along the S.S. 36 “del Lago di Como e dello Spluga”, occurred on October 18, 2016. The failure had a high impact on the Italian society since it caused the death of a car driver and several wounded. The bridge was built between the 1960 and 1962, with a Gerber scheme deployed over 4 supports (Fig. 4(a)). The central deck, $24.60 \mathrm{~m}$ long and $4.40 \mathrm{~m}$ wide, was constituted by 5 precast and prestressed I-beams. Gerber supports were $0.575 \mathrm{~m}$ high, with and ordinary reinforcement as shown in Fig. 4(b) and Fig. 4(c). Before the collapse, the bridge was subjected to several impacts by underlying moving vehicles [1]. This was due a non-adequate free height of the overpass $(<5 \mathrm{~m})$. After these events, the saddle was repaired with rebars and CFRP installments (Fig. 5(a)). However, those interventions could not renovate the shear fracture propagated over the saddle and significant presence of humidity was often detected when inspected (Fig. 5(b)). This was mainly due to the produced misalignment in the dapped-end (2.5 $\mathrm{cm})$ due to the repairs, which constituted a stagnation point for running water [2].

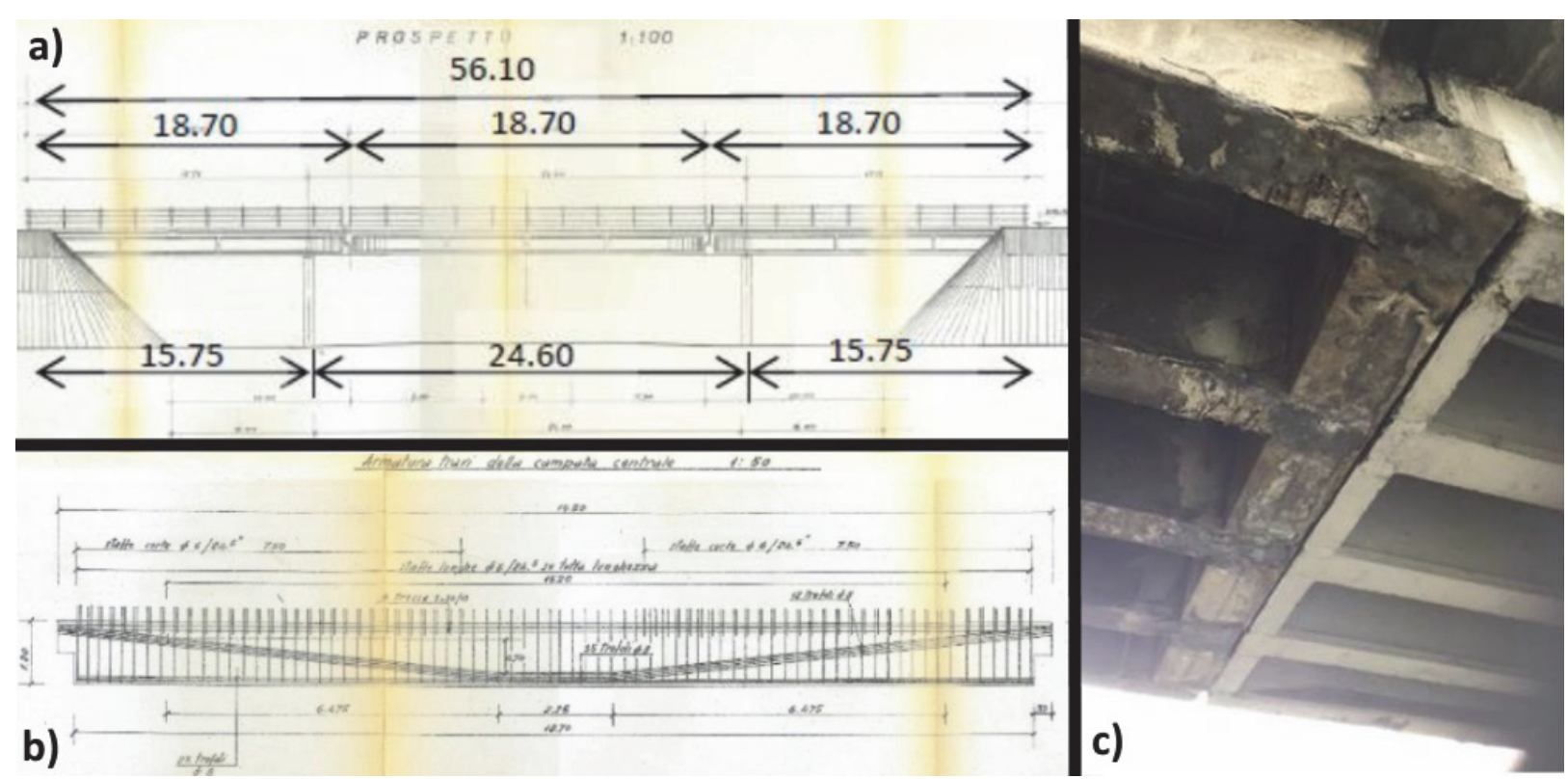

Figure 4: Overview of the Annone overpass [1] (a); Geber support reinforcement, design (b) and investigation (c).

The collapse occurred when a 107.6 t heavy 8-axels truck went across the deck with a low moving speed (Fig. 5(c)). Once the load was carried entirely by the central beam, the external repaired dapped end corbel collapsed due to the vertical reaction established for supporting the beam. Total weight on the structure was approximately $172 \mathrm{t}$, which is $10 \%$ higher than the maximum design load adopted equal to $155 \mathrm{t}$. However, this excess should have been overcome in the safety factor. This bridge was catalogued as category II by Italian Building Codes [3], but the safety requirements were not fulfilled by the structural properties. Investigation [1] have demonstrated that this failure was compromised by:

- an initial design flaws in the dapped-end corbel that significantly reduced the ultimate load; 
- reinforcement in the precast beams was not enough to ensure a category II bridge classification;

- the presence of a shear fracture along the dapped end corbel promoted the oxidation of the reinforcement bars in the joint;

- the passage of II category loads (more than 100 per year) puts frequently the structure close to its ultimate bearing capacity.

- the eccentricity produced by a transit misaligned by the carriageway central line significantly increased the loading in the external dapped end joint.

These results have been produced by detailed destructive analyses that can not be carried out for an existing structure. This means that the only control parameter that we can adopt in these cases is load checking and protective device installments for delicate parts, as Gerber supports.
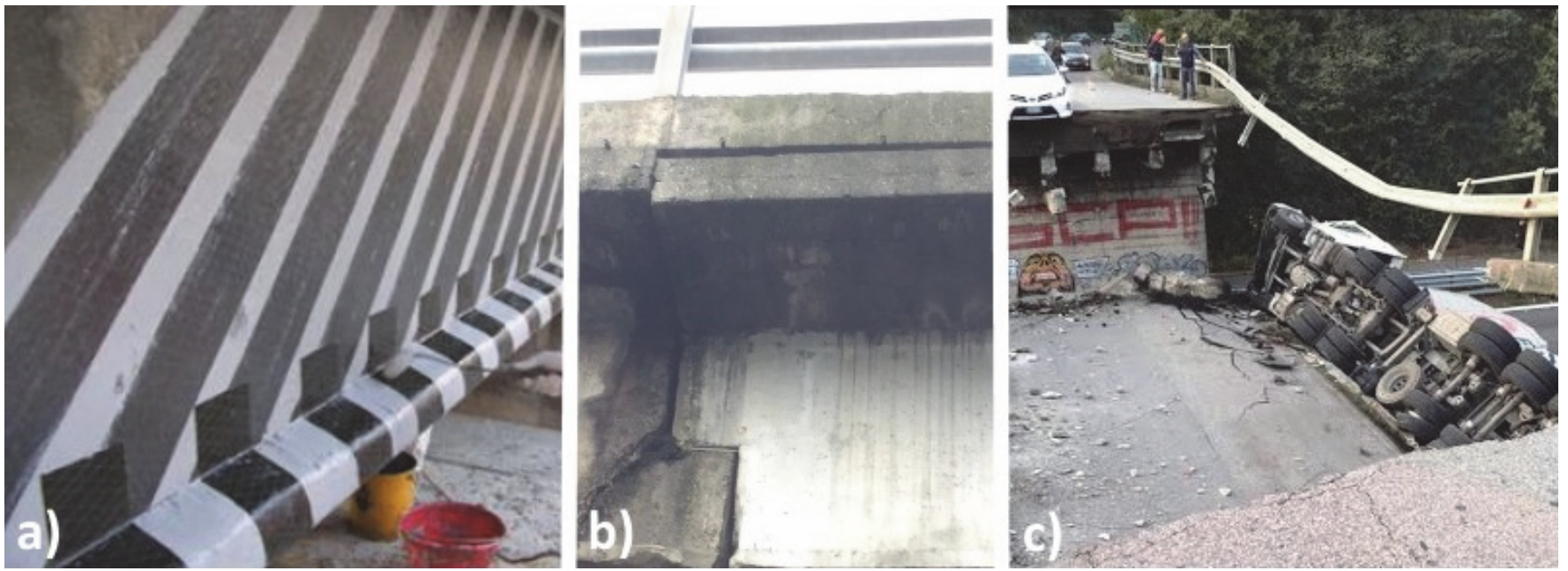

Figure 5: Dapped end corbel conditions before the collapse (a); humidity presence and water stagnation (b); failure loading configuration (c) [1].

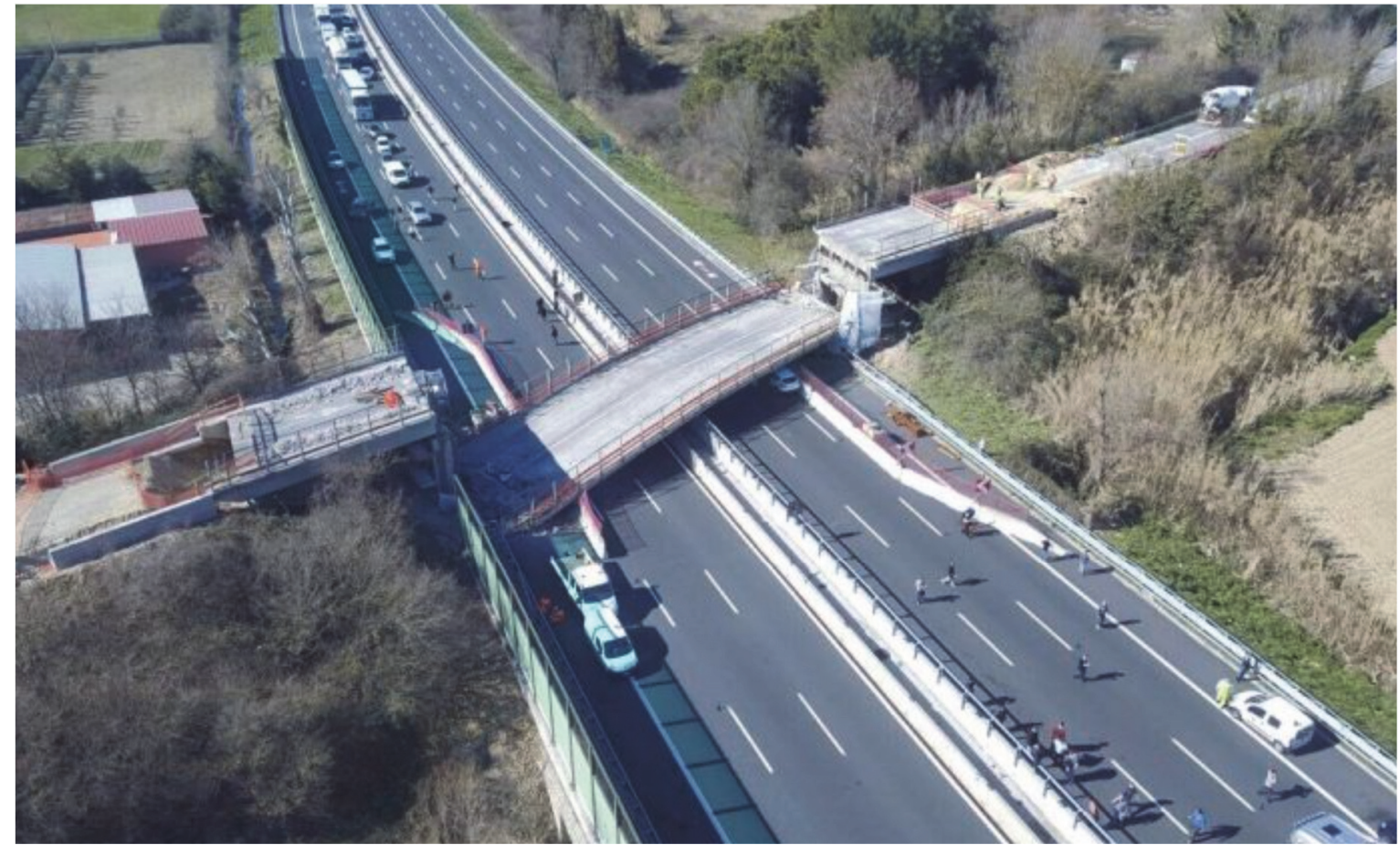

Figure 6: Ancona overpass after the collapse (from web site www.cronacheancona.it). 


\section{Ancona overpass: movement operations}

This collapse occurred on 9 March 2017, near Ancona, along the A14 Italian Highway. The bridge (167 at km 235+800) was constituted by a steel-concrete composite deck $16.5 \mathrm{~m}$ wide and $36 \mathrm{~m}$ long with a simply supported beam scheme (Fig. 6). When collapsed, the deck was uplifted for maintenance operation and it was supported by a temporary structure. The deck fell on the underlying highway, causing the death of 2 people that were transiting underneath.

The case of the collapse of the overpass on the A14 motorway near Ancona is quite different from the others and was caused only by a resounding error during the execution phase. The works involved the adjustment of the altimetric height of the overpasses, consisting of raising the decks, creating an extension of the support structures and the re-profiling of the associated ramps. The lifting took place through the use of hydraulic jacks with few centimeters steps, after positioning of steel plates for distribution. The appointed subcontractor to perform this specific process decided to replace the supporting steel plates with similar plates in neoprene, much lighter to move. Numerical analyses conducted during investigations by prof. Tarantino highlighted how a difference between the temporary supports of a few millimeters generates horizontal forces not compatible with the shear deformability of the numerous neoprene plates stacked on top of each other. This generated an unexpected bridge horizontal displacement and the collapse occurred. Further details are under investigation.

The lesson that can be obtained from this incident reinforces the conviction that in the execution phase often nonspecialized and often improvised workers are used.
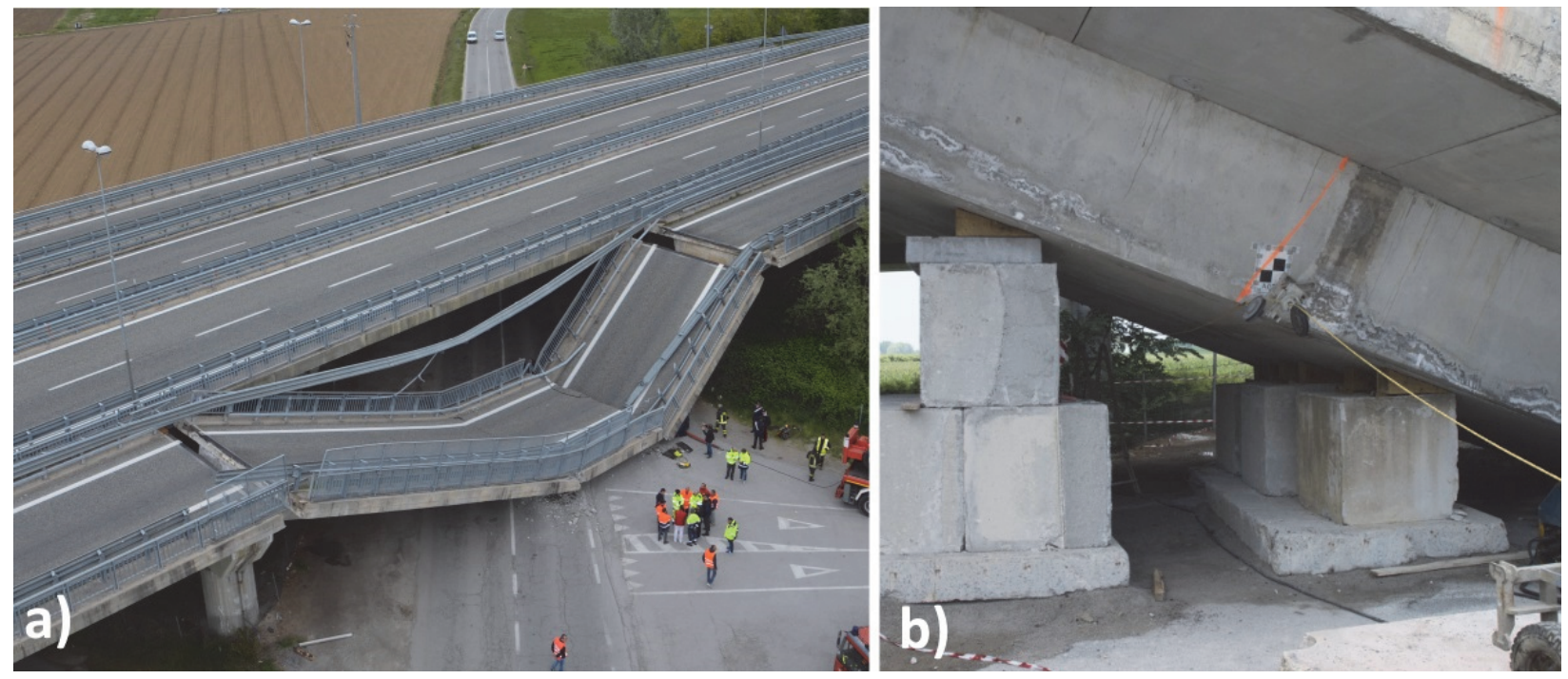

Figure 7: Overview of the collapsed Fossano bridge (a) and structural scheme (b).

\section{Fossano bridge: construction and design}

The collapsed overpass is one of the 108 that constitutes the Fossano (Cuneo) bypass road. This road has several viaducts, and the one involved in the failure is one of the ramps of La Reale Viaduct, where it crosses the S.P. 165. The collapse occurred on April 18, 2017, and luckily (2.45 p.m.) no vehicles were going across or underneath the structure. The sudden collapse took place without out-of-plane displacements (Fig. 7(a)). A modest slip ahead in one of the bearings has been identified in the collapsed configuration. The structure was a simply supported beam, $30.80 \mathrm{~m}$ long and $8.90 \mathrm{~m}$ wide, constituted by a multiple-box post-tensioned beam and by a in-situ casted slab. The section was realized by connecting two concrete precast U-elements by a shear-key casted in situ. In the longitudinal direction, the bridge was built in 3 segment, the central one $11.50 \mathrm{~m}$ long and the lateral ones $9.35 \mathrm{~m}$ long. The connection between the segments was realized by an in-situ casted concrete joint $0.5 \mathrm{~m}$ wide (Fig. 7(b)). Post-tensioning system constituted in 8 parabolic cables, each of them made by 190.8 " strands. Total weight of the structure was about $400 \mathrm{t}$. The collapsed structure evidenced an intact joint and a collapsed one, together with an evident shear failure where the bridge impacted the ground. For this event, several information can not be given at the moment due to secrecy related to the running investigations. Visual inspections consented to affirm that the collapse mechanism was triggered by a shear failure in one of the joint due to the absence of the equilibrating action of the prestressing (Fig. 8). This means that in some part between the support and the intact joint, the cables were damaged. Visual inspections immediately also demonstrated that the cables did not have sufficient grout protection in the collapsed joint area (Fig. 9(a)). The damage was not compatible with a 20 years old 
concrete structure damage scenario, and moreover, the overall external condition appeared healthy (Fig. 9(b)). This unusual structural failure, and the fear of a systematic bias, has been followed by detailed analyses and the structure has been dissected in order to establish the causes. To date, the vulnerabilities of this structure can be summarized as follows:

- absence of ductility and structural robustness, there is no redundancy in the prestressing device;

- inadequate grout injection inside the cables, which led the water to a preferential way inside the sheathing;

- total non-accessibility for structural inspections.

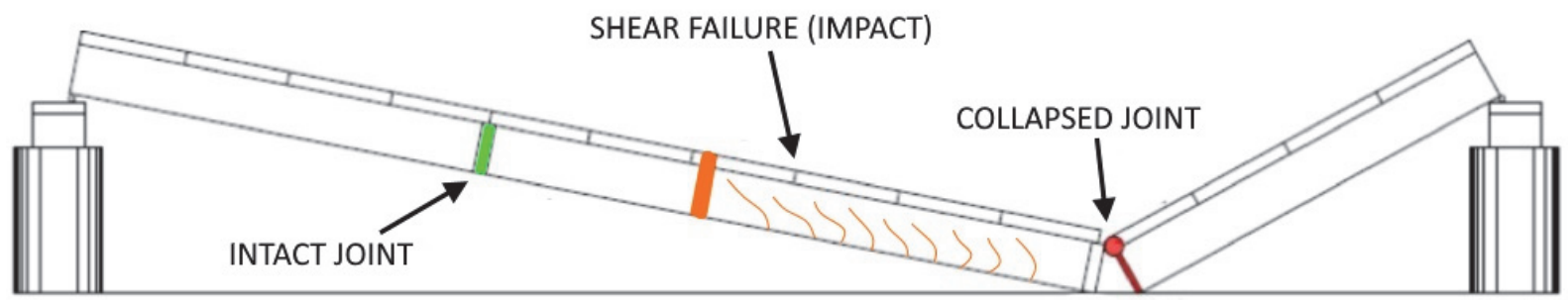

Figure 8: Collapse mechanism.
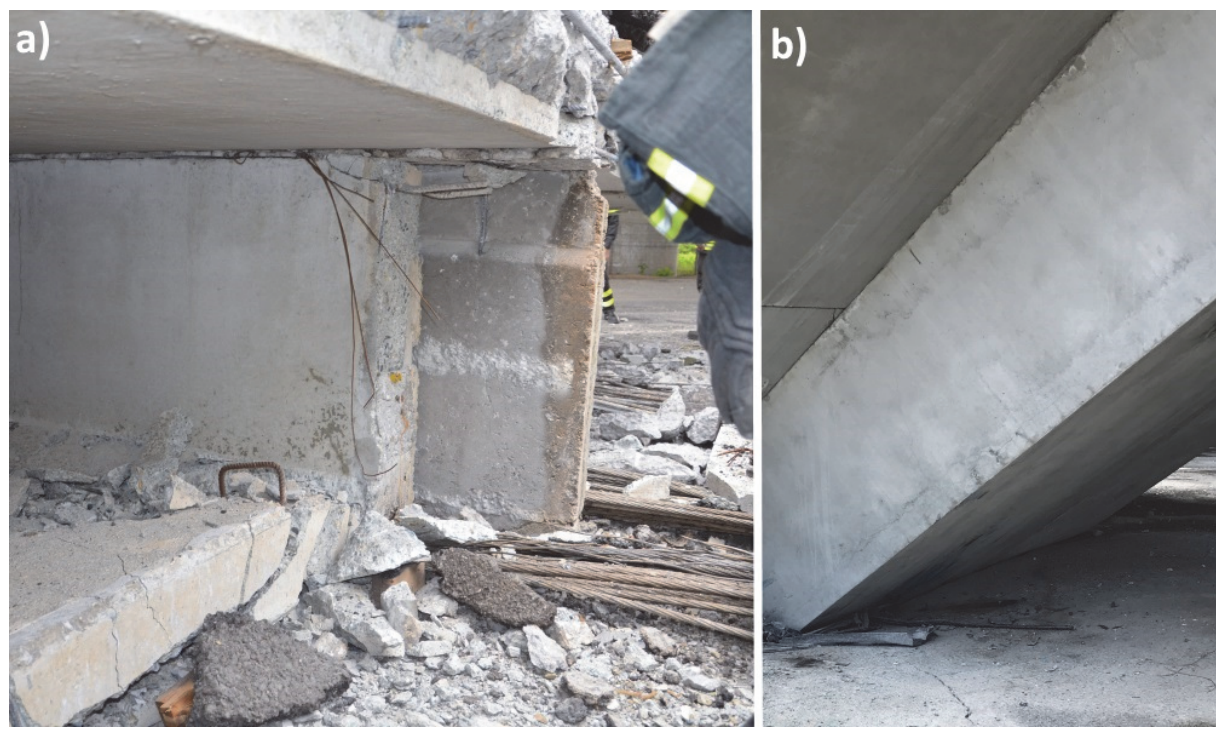

Figure 9: Prestressing cables in the collapsed joint area (a); external concrete conditions (b).
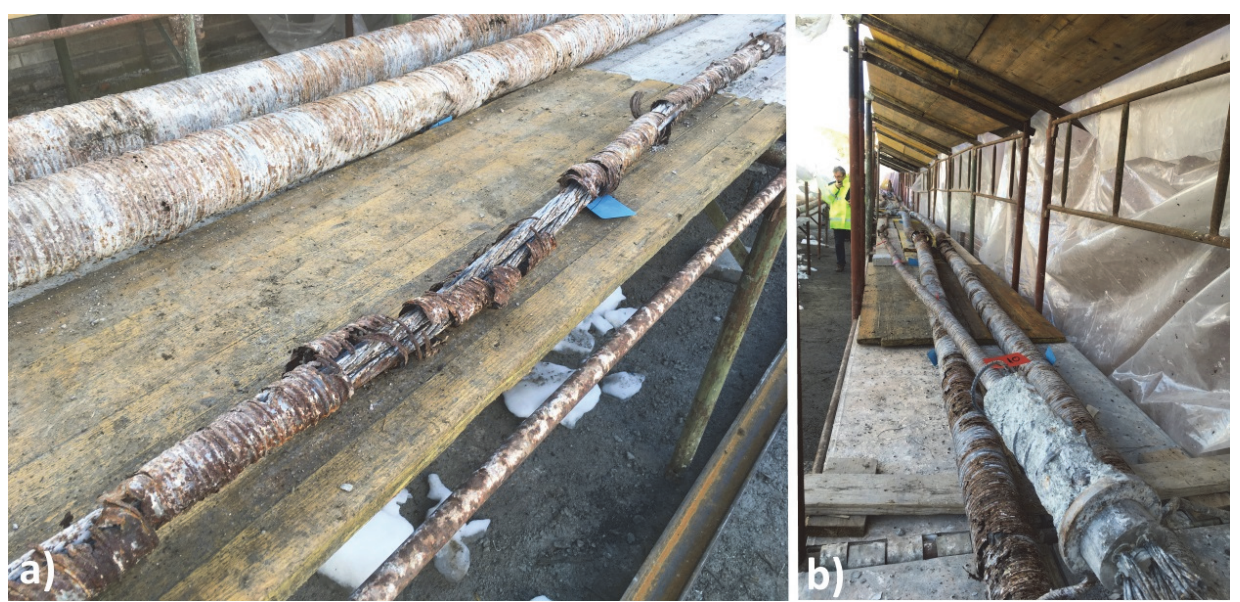

Figure 10: prestressing cables, extracted and analyzed. It is possible to note the direct correlation between grout content and oxidation rate of both sheathing and strands. 
The number of the analyses that have been carried on investigating this collapse was enormous: simulated rain tests to locate the water gateways, chemical tests for the crystallized residuals and molds, and each segment was carefully demolished and each cable was extracted and inspected (Fig. 10). A complete autopsy was conducted on the bridge. When the investigations will be finished, the civil engineers will learn a lot from the final reports of the investigation committees.
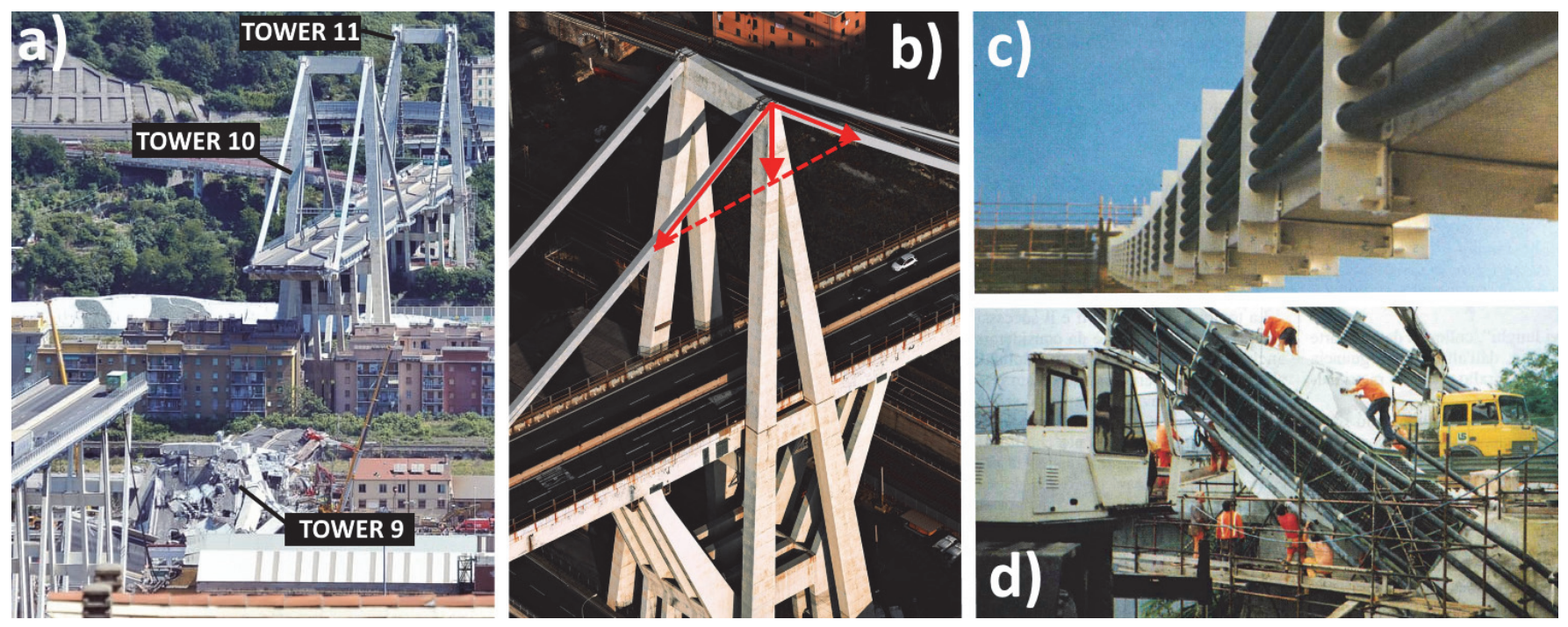

Figure 11: overview of the Polcevera bridge collapse (a); structural scheme of the tower (b); stay cables replacement intervention (1993) (c,d) [4].

\section{Polcevera bridge: design, maintenance and durability}

On August 14, 2018, the Tower 9 of the Polcevera bridge, abruptly collapsed on the underlying industrial hub, Polcevera river and rail track of the city of Genoa (Fig. 11(a)). This collapse represents a categorical failure for the Italian Structural Engineering community. Whatever the causes of the collapses would be addressed to, object of the undergoing investigations, it is evident how there have been errors in the check procedure. Starting from the design (1960), the structural system ("cavalletto" [4]) that realized the tower relied on the balanced compressive force along the lateral columns (Fig. 11(b)) coming from the stays. The assembled framed tower, plus a four-point supported deck, exhibits a complete absence of robustness and structural redundancy, which means that in case of failure of one of the components, there was no control in preventing a catastrophic collapse [5]. Many colleagues affirmed and condemned the designer for the collapse. As written in the introduction, we can affirm that the lack of robustness was normal for the typological structures of that era and consequent to the available tools in the 60'. It is easy today to perform analyses for highly indeterminate structures by using computers, but it was not at that time. The structures were designed by using the simplest possible schemes, in order to have easier calculation to be made. Consequently, no ductility expedient, at any scale, was adopted to exclude fragile collapse [6]. Robustness and ductility are two design control parameters for structural safety in the ultimate state of collapse. Moving forward along the chain, maintenance and monitoring are two control activities that usually go along with an important bridge structure. Because of its audaciousness, Polcevera bridge has been continuously investigated and consolidated over the years. Along the 70s, the designer himself, started with regular visual inspections [7], while over the ' 80 s a distributed restoration of the concrete components was carried out [4] starting from the towers and then moving through the deck. In 1993, a detailed inspection through the insertion of an endoscopy inside the stays of the Tower 11, evidenced a severe oxidation of the metallic protective membrane and of the strands themselves. Additionally, significant presence of humidity and absence of grout were reported. Moreover, some of the strands appeared slacked or sheared, sign of a tensile rupture due to steel cross-section reduction [7,8]. This preoccupying scenario advised the entire structure management authorities over the risks of material decay due to micro-cracking in the prestressed concrete. In fact, the concrete section of the stays was designed to be subjected to light but continuous decompression-compression cycles due to live loads. The peculiar cables disposition, core of the M5 patent [9], had the aim to avoid large stress variations in the steel strands, but this was possible only with a magnitude of the tendon force close to the ultimate one. All the described conditions led the structure to a quickened state of material decay and the entire sets of stays of the Tower 11 were replaced with an external prestressing system (Fig. 11(c), Fig. 11(d)). After this massive intervention (12 cables $\phi 150 \mathrm{~mm}$ with 22 0.6" diameter strands for each stay and 4 months of work with reduced 
traffic), many other maintenance and monitoring activities have been performed over the viaduct [10]. Most of the monitoring regarded the health condition of the strands of the remaining towers [11], while the repairing affected the carriageway slabs. When Tower 9 collapsed, a replacement intervention of its strands was planned for the following two months, and ongoing maintenance was present on the deck.

\section{MAIN BRIDGE VULNERABILITIES AND CONTINGENCY SOLUTIONS}

$\mathrm{M}$ any bridges of Italian road infrastructural network are now between 50 and 100 years old. Throughout this period of time, materials, technologies and traffic loads significantly changed, together with the community necessities. The challenge for a new record span or a lightweight design mutated, in the scientific and technical community, in favor of the challenge of diagnosing and securing the inherited infrastructural heritage. Italy counts around 60000 bridges (a detailed census does not exist), more than half in high seismic areas [12]. Failure collapse probability assumed by European Building Codes [13] for a new structure is mandatory to be less than 1E-6 per year. With a failure ratio of 1.25 bridge/year, the situation produced by the vulnerability of the existing buildings has a detrimental factor of 13. The vulnerabilities, as evidenced in first part, are essentially connected to the unawareness of the material degradation or to the lack of devices in avoiding fragile collapse.

\section{Durability in concrete bridge engineering}

The first long span concrete bridges have been erected at the beginning of the last century. Examples like the Ponte Risorgimento (Hennebique, Rome, 1911) or Saint Pierre du Vauvray Bridge (Freyssinet, 1923) were considered pioneering works and stands still today as symbols of innovative conceptions. It is, however, after the second World War that under the continuous push of the economic revolution the concrete industry had its widespread diffusion. The sole construction of the A1 Highway Milan-Napoli, started on 1956, brought to the country $800 \mathrm{~km}$ of heavy roadway and 400 bridges in less than eight years [14]. Between 1954 and 1970 more than 20 bridges were erected over the Po river [15]. The structural scheme was commonly the multi-span simply supported beam or the Gerber cantilever. This choice relied on the availability of precast prestressed concrete beam. The introduction of prestressing, around 1950, drastically increased the achievable spans and the better use of the concrete compressive strength. Moreover, the lack of numerical methods, especially for prestressing loss, did not allowed the use of continuous beams or statically undetermined framed schemes. Italian Building Codes, drafted in 1960 (c. n. 94 7/03/1960), regulated the use of prestressing, but, with today's knowledge about concrete chemistry and long-term properties decay, they appear tremendously inadequate in fulfilling the durability requirements. An example extracted by the codes states that " $[\ldots]$ the water content must be the least possible to guarantee the workability of the mixture without exceeding the 0.45 weight ratio with cement and aggregates" or " $[\ldots]$ to execute frequent grain size checks to fulfill the maximum compactness". These are all qualitative recommendations that demonstrates the lack of a tangible knowledge of the time-dependent behavior of the concrete in its crucial years of widespread diffusion.

One of the main factors that influences corrosion of reinforcement is the porosity of the mixture. This allows the aggression of the iron by the external chlorides and promote carbonation. Porosity has a direct correlation with water content and increasing aggregated grain sizes [16]. The promoted studies in the early $1970[17,18]$ set a milestone in concrete technology, evidencing the carbonation phenomenon and the quantitative role of porosity. Furthermore, they facilitated the introduction of super-fluidifying solutions, which exploited the power of chemical additives in reducing drastically the water content with an appreciable workability. At the same time, minimum concrete cover prescription and efficient detailing for diverting running water were introduced in the upcoming building codes [19]. In 1979, Morandi published an update [20] on the Polcevera bridge behavior after twelve years of service. It was then clear that the wall cracking represented a problem for long-term performance of the structure, especially for an aggressive environment like the one where the bridge was situated. Polcevera viaduct is $1 \mathrm{~km}$ distant from the sea and in the underlying industrial hub there was, until 2005, a steel production plant. This means that the wind that climbs back the city coast brought not only chlorides, but also sulphur dioxide in contact with the structure. Sulphur dioxide, when combined with carbon dioxide, becomes sulphuric acid that reacts with cement transforming lime in salt composites that can be washed out by rain. As suggested by Morandi in [20], and as illustrated in section 1, in the 80s the concrete of the Polcevera towers had a surface polishing and restoration treatment. Literature does not report any details about this repair intervention, but we know from [20] that the Author suggested the exposure of reinforcement, rust removal, epoxy covering and the addition of a protective layer with a wire mesh. Form picture of this intervention (Fig. 12(a)) it is possible to see that, in some parts, an actual wire mesh was embedded in the new surface concrete layer. From Italian building magazines [20,21] we know that 
the epoxy covering was substituted with the Emaco S88 retained shrinkage grout and an Emaco Bianco white painting (Fig. 12(b)). Images of the collapsed Tower 9 prove the presence of this protective layer, but at the same time is possible to observe a neat discontinuity between the old and the new surfaces (Fig. 12(c)). Today, the state of the art for the same intervention prescribes that the removal must occur for all the thickness of the corrupted concrete, and complete bonding has to be assured between old and new surfaces to avoid stagnation and contaminant penetration [22].

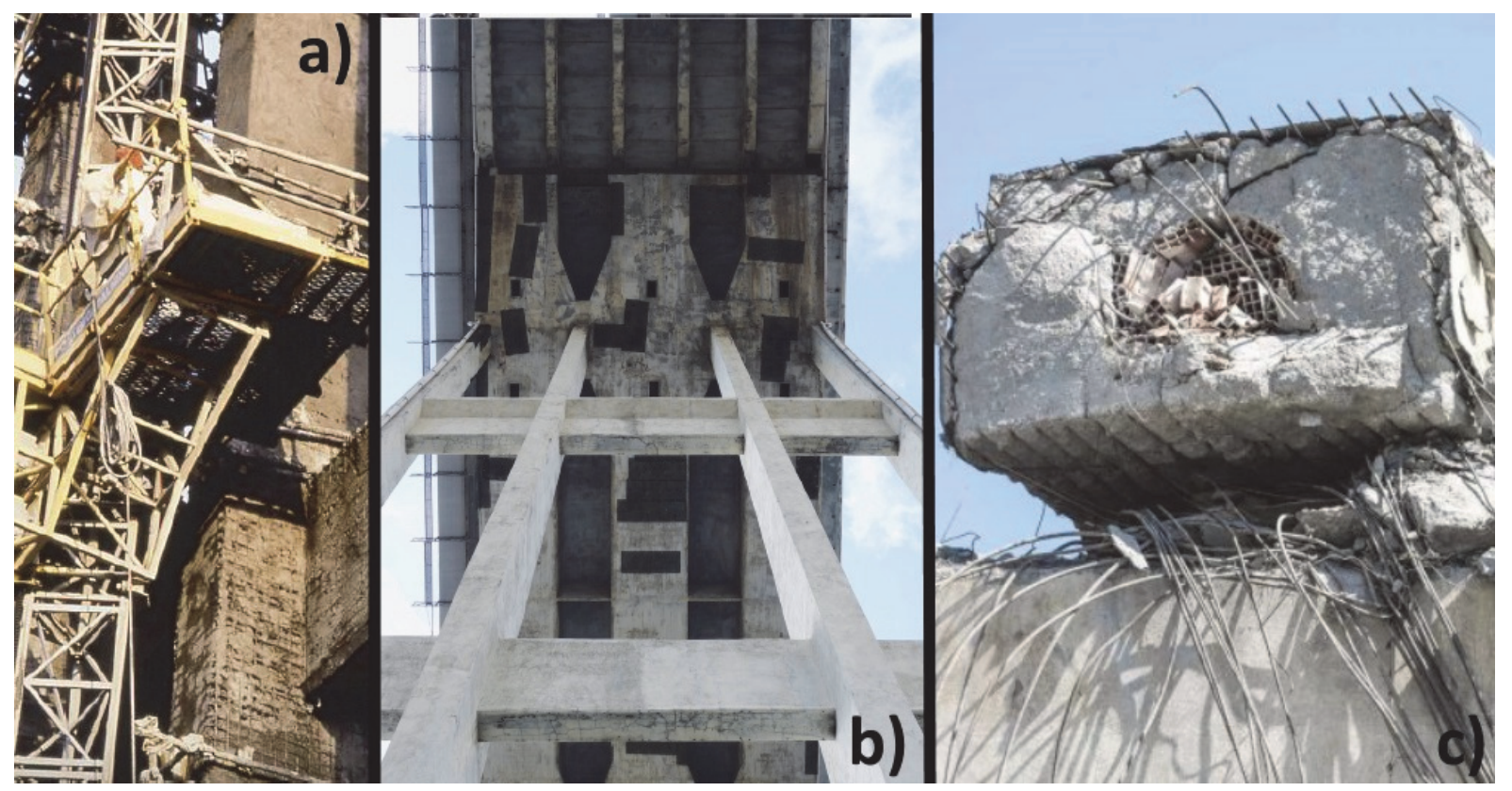

Figure 12: Repairing of one of the tower of the Polcevera viaduct [17] (a); white covering of Tower 9 (b); ruins of Tower 9 (c).

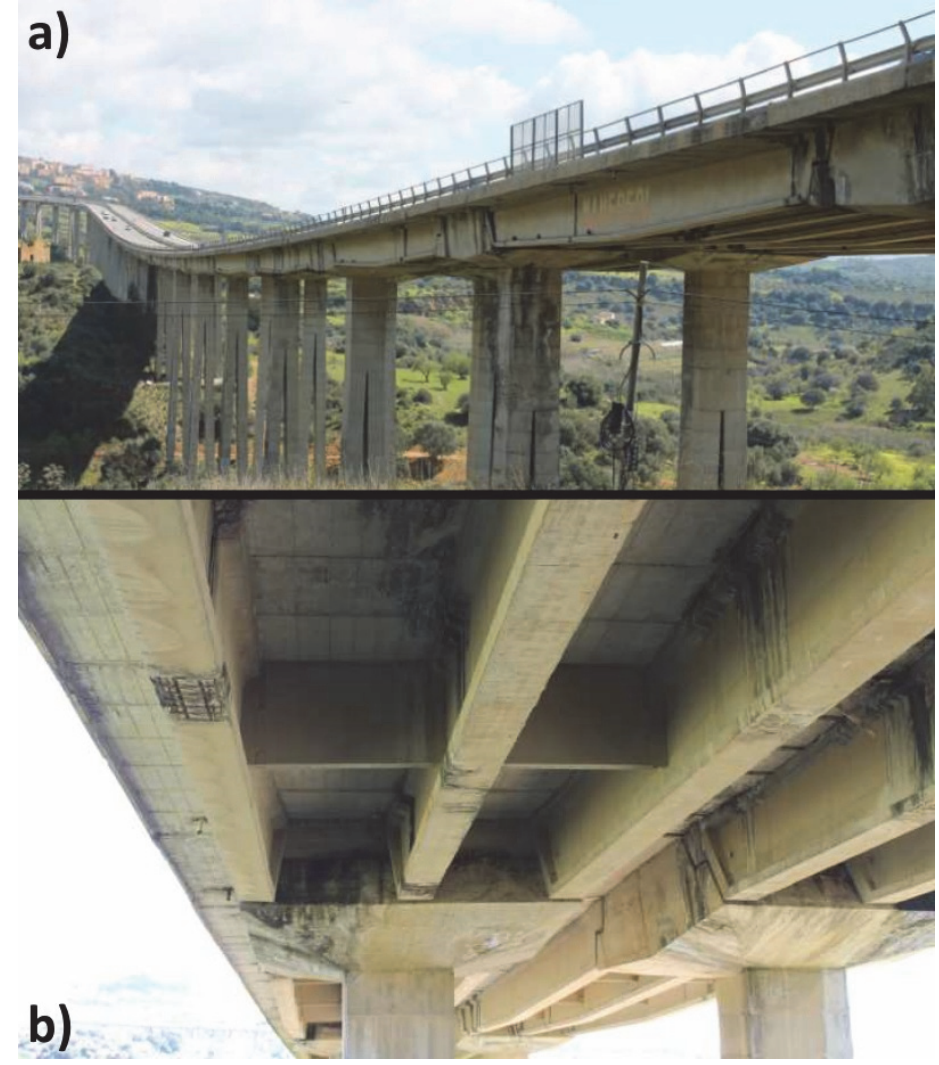

Figure 13: Overall view of the Akragas viaduct (a); deck detail (b) [23]. 
Throughout the same years, the Akragas Viaduct (S.S. 115-AG, Agrigento, 1970) was erected in Sicily. The design, by Morandi, considered a total length of $1400 \mathrm{~km}$ skewed viaduct with 31 spans, each $44 \mathrm{~m}$ long (Fig. 13(a)). The deck, $10 \mathrm{~m}$ wide, was realized by a grillage of 3 unbonded prestressed I-beams, 5 transverse beams, and a precasted pavement (Fig. 13(b)) [23]. Support for each beam consisted in a couple of reinforced concrete A columns, with a maximum height of 60 $\mathrm{m}$. To date, these latter elements represent the key vulnerability of the structure. Each column was erected through a concrete concave precast box that works both as scaffolding (in the pouring phase) and as shear resisting element (Fig. 14(a)). It is reasonable to think that visible damage is due to the concave shape of the external box. When shear forces required confinement, the bars pushed against the box bulged the internal part as visible in Fig. 14(b). Together with the static problems, the retrofitting intervention has the aim of improving the seismic behavior by providing sufficient shear strength and ductility: a new element and the recovering of a confined state for the concrete of the core.

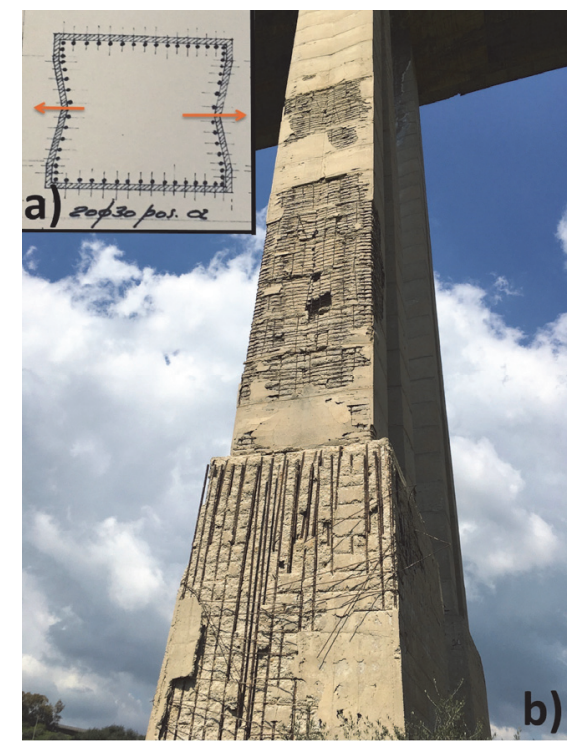

Figure 14: Column details (a); state of decay of the columns (b).

Petrulla Viaduct characteristics have been discussed in section 1. The oxidation of the reinforcing and of the prestressing cables (Fig. 2(a), Fig. 2(b)) occurred due to an inadequate protection by carbonation and water seepage. Through the results of the vulnerabilities, four different restoration interventions have been proposed, corresponding to the observe damage degree (Fig. 3(a), Fig 3(b)). For the level one (G), the removal of the actual concrete coverage and corroded bars, followed by their complete refurbishment, was suggested (Fig. 15(a)). Considering the second level (Y), to assure the adequate safety factor, the installment of a metallic plate was suggested to reinstate the base of the I-beam. This plate was supposed to be connected to the web through two lateral bolts and a glued to the base of the I, previously abrase. The injection of epoxy resins realized the final sealing and the protection from further corrosion. For the third level (B), the intervention is the same of the discussed previous one with the additional injection into the prestressing cables with lowviscosity epoxy (Fig. 15(c)). Concerning the worst damage case (R), the corroded section area of the strand must be recovered to fulfill the safety factor. In order to do so, an external prestressing was suggested, connected to the sealing steel plates and the cable header (Fig. 15(d)).

Considering now the case of La Reale Viaduct (Fig. 7(a)). Durability problems are overcome by the peculiar shape of the deck and its modular assemblage. To avoid a fragile collapse, the structure must improve its robustness. Since the analyses of the safety of the infrastructure are still under exploitation, different levels of intervention are suggested towards the observed damage pattern. For the spans that will evidence lack of cable protective grout, epoxy injection would be necessary to stop di advancement of corrosion. This operation could result particularly difficult to do because of the inaccessible boxed section. A frequent problem in bridge concrete walls is concrete spalling and exposure of reinforcement. This situation is particularly dangerous when the exposed reinforcement realizes the primary load carrying system, i.e. dapped-end corbels (Fig. 5(a), Fig. 5(b)). Under this circumstances, health of the steel is essential to exclude a sudden collapse due to shear failures. Considering the numbers of the existing artifacts, sometimes just blocking the advance of corrosion represents a good strategy to keep reasonable safety factors while retrofitting is pending. This strategy cab be implemented by the use of sacrificial anodes (galvanic protection) directly connected to exposed reinforcements (Fig. 16) [24]. These anodes, usually realized in zinc-based compounds, guarantee local protection to the 
steel by the higher electronegative power of the sacrificial anode. The monitoring of these devices can be executed by simple electronic tester that measures electricity rates in the anodes. When the exposed reinforcement is large and interconnected (i.e. a wire mesh), an alternative solution is the cathode protection. In this case, an electric current is supplied to the steel by an external generator, shielding the reinforcement from corrosion.

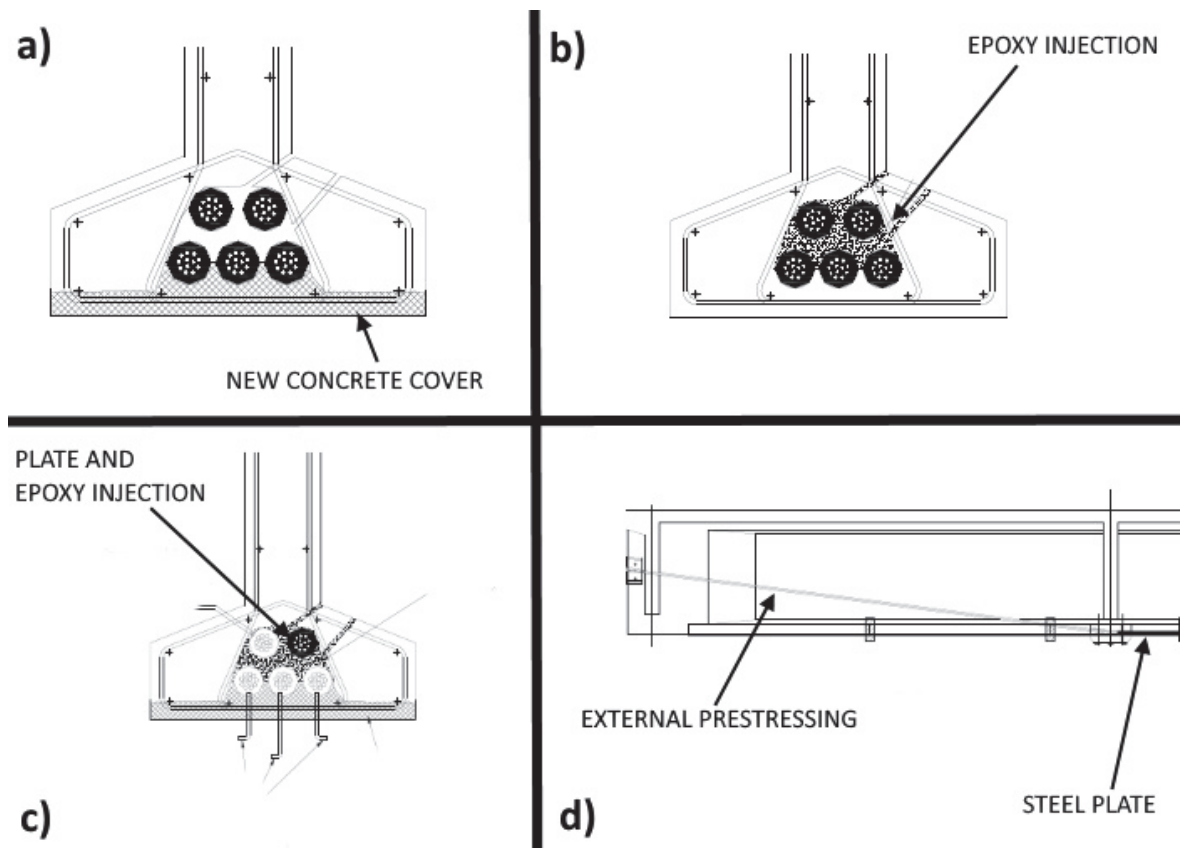

Figure 15: Suggested retrofitting. Level 1 damage (a); Level 2 damage (b); Level 3 damage (c); Level 4 damage (d).

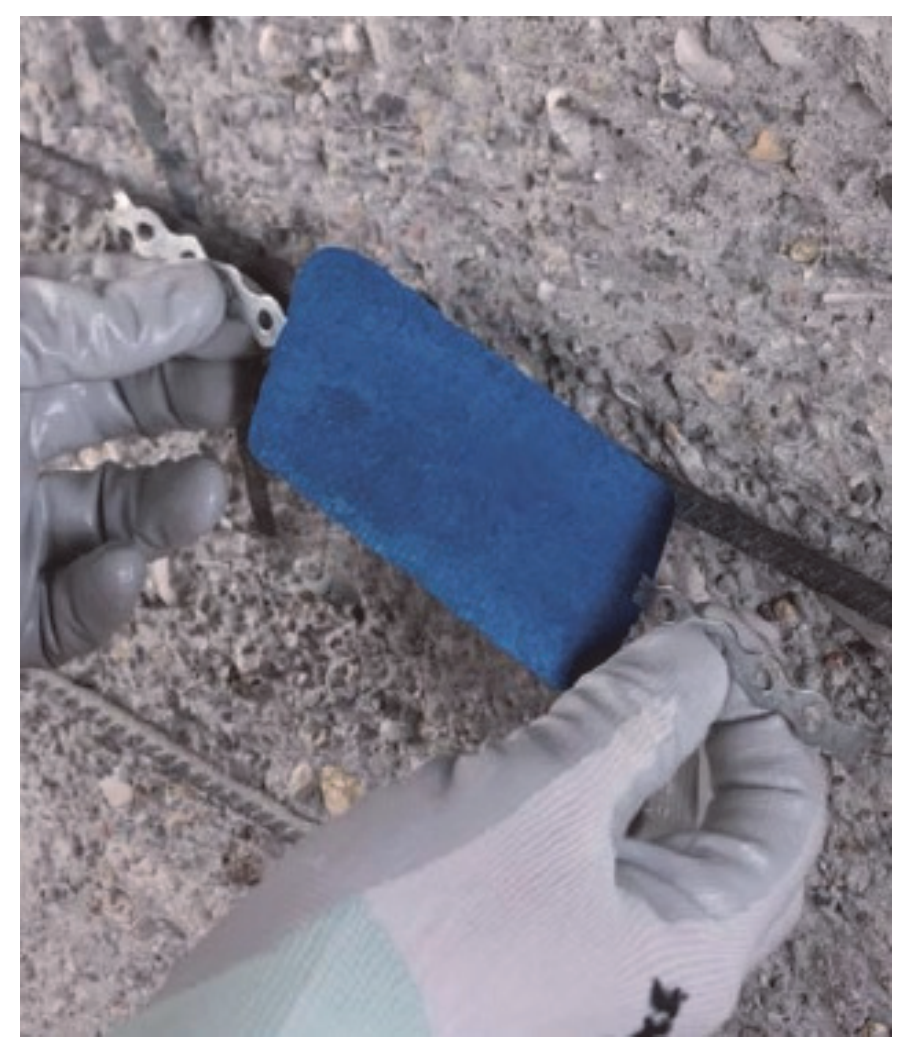

Figure 16: galvanic protection: sacrificial anode [Copyright: Mapei]. 


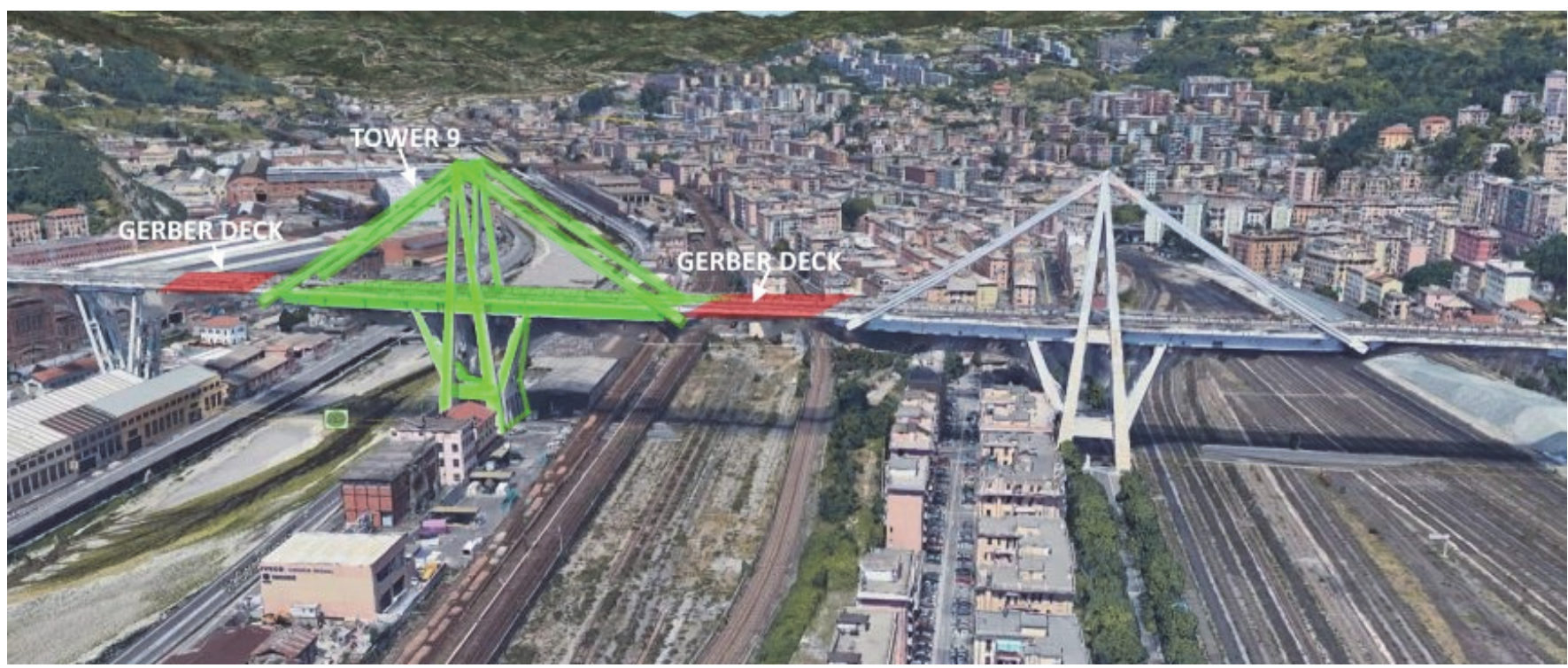

Figure 17: Involved structure in the collapse: tower and Gerber decks.
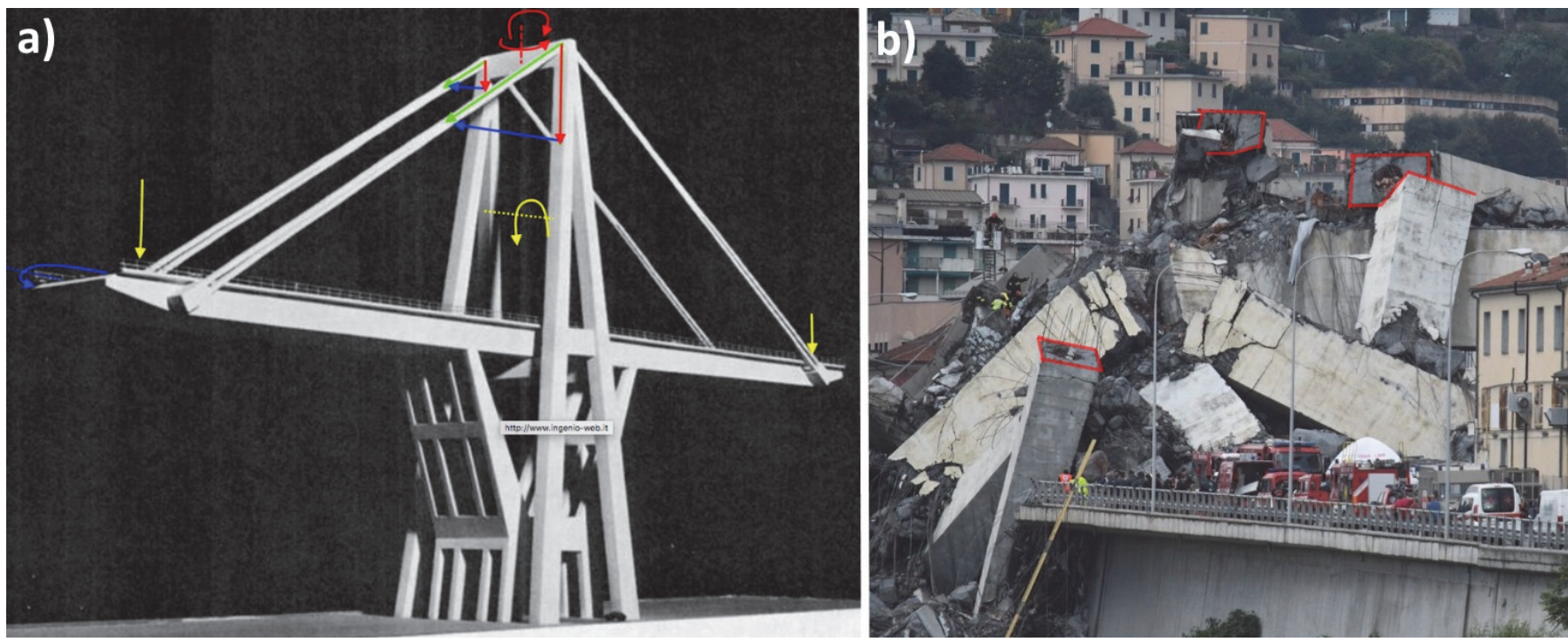

Figure 18: resisting mechanism of the Polcevera Tower: equilibrium in the three planes [www.ingenio-web.it]. (a); planar failure surfaces (b).

\section{Existing road infrastructures vs. robustness concept}

One of the shocking aspects of the Polcevera Viaduct collapse was its catastrophic nature. Even if the causes are currently under investigation, it is clear that the failure of one component has been followed by the entire structure, composed by the tower (green, Fig. 17) and two simply supported Gerber decks (red, Fig. 17). As anticipated, the equilibrium of the system rests upon the balance between the symmetry axes of the tower (Fig. 18a). A lack of balance in one of the two directions of the equatorial planes induces a flexural moment in the deck plane that can lose in-plane stability and could break due to to unbalanced compressive forces (blue, Fig. 18(a)). Under these circumstances, the in-plane twisting could cause the slip of the Gerber decks, that without a vertical support become free to fall. At the same time, a disequilibrium in the plane of the bridge direction induces torsion and bending moment to the double framed A tower (red, Fig. 18a). This structure could not have the ductility capacity to resist at such asymmetric stress, because of the limited rotational capacity at the base (wider) and the lack of redundancy for force redistribution. Moreover, unbalanced forces in the plane of the stays causes deck uplifting on one side and subside to the other. This mechanism, could be again 
responsible for the support loss of the Gerber deck and the rupture of the deck due to bending in its plane (yellow, Fig. 18a). An asymmetric fall of the deck causes and inevitable impact with the intermediate deck support that would find themselves dragged into the collapse. Finally, the observation of the Tower 9 ruins allows an additional comment: many of the parts of the tower broke with planar surfaces, evidencing low or nonexistent process zone and plastic hinge creation. These planar surfaces represent probably the casting phases of the vertical structure. This would imply that (i) no sufficient rebars content was present in that zones, or (i) the boxed section had not sufficient plasticity reserve (red, Fig. 18b). In the end, at this level of knowledge, the lack of structural robustness can be addressed to these factors:

- the low number of stays elements that causes zero redundancy in deck support;

- the low rotation capacity of the A framed lateral tower and its limited redistribution;

- the statically determined scheme for the entire viaduct, which causes higher displacements (and cracking as a consequence) and domino effect collapse;

- the low ductility at member scale;

- the intrinsic sudden loss of strength of prestressing technology.

Lastly, from a mechanical point of view, concrete dissipation energy in compression is highly dependent on the size of the structure. Experimental results always evidenced a dependency in evaluating the compressive strength to the specimen size and the testing machine (that is why today we use standard) [25]. We know from literature that the post-peak branch of the load-displacement curve is governed by macrocracking, after the coalescence of the initial micro-cracks. The energy dissipation is a surface-dominated phenomenon and damage localization occurs in small concentrated zones, but this is true only for "small" specimen size; nevertheless, for larger structural dimensions the energy dissipation should be a volume-dominated process and damage is more spatially distributed. Experiments have evidenced how, avoiding friction, there is no noticeable deviations in concrete ultimate strength due to specimen dimension, whereas strong variations are observed for dissipated energy in compression, with a catastrophic nature for "big" scales [26].

The retrofitting intervention proposed for the Petrulla viaduct (Fig. 15) had also the purpose of increasing the robustness of the structure. Local plates and the external prestressing made recover structural continuity to the beams. Furthermore, the external cables are easy to inspect and check for integrity. This opportunity represents also a form of robustness because of the redundancy of controls. On the contrary, structural arrangement like the one of the Fossano Bridge requires to retriever firstly the structural coherence. The joints represent a discontinuity towards the fragile shear mechanism. This means that, if the cables are unbonded across the joint area, there is no possibility for the vertical loads to reach the supports once the cables are broken. This could be easily testified by looking at the intact joint that resisted the impact on the ground when bridge failed (Fig. 7(a)). Moreover, inspections in the web and epoxy void injections seems unfeasible due to the section shape. In the same way, external prestressing is rather impassable, since it is unknown the adequate force and steel to apply. A promising solution is represented by resurfacing the concrete beam with a steel carter that works both in shear and flexural regime (Fig. 19). The mandatory condition for this repair intervention is the absolute adherence between the steel sheathing and the concrete, in regard to congruent strains and humidity proofing [27].

\section{INNOVATIVE TECHNOLOGIES AND INVESTIGATION METHODS}

$\mathrm{D}$ ealing with existing bridges implicates a first step in building knowledge on the actual conditions and properties of the structure. Scientific community groups all the investigation methods in two categories: Structural Health Monitoring (SHM) and System Identification (SID). SHM is a field of study that has the aim to ascertain the haleness, defined as a function of desirable structural properties as variables, once referred to a state base of safety. To do so, structure is periodically sampled by installed sensors, and after a signal processing phase, statistical analyses determines the health function [28]. SID, on the opposite, can be performed once and has the objective to quantify the actual features of the artifact. Considering both SHM and SID, the procedures panorama is extremely fragmented and it lacks an organic interpretation scheme. The vast set of methods varies among dynamic to static regime, passive to active stimulation, and remote to field sensing. To mention some techniques and systems, we have Acoustic Emission, Fiber Optic Network, Piezoelectric Active Sensors, Accelerometers Modal Correlation, Guided Wave Sensing, Tomography, LIDAR Displacement Detection and so on. As recently criticized by several authors [29,30], even each available method has a huge number of different patented technologies behind. Moreover, accuracy is strictly dependent on the prior knowledge of the monitored structure. Using a medical analogy, it is like having a disorganized number of specialized 
clinics without a general diagnostician that performs a fast screening with limited number of symptoms. But the numbers discussed earlier and the projections for the needs of infrastructures of the future urban population [31]: the need for doctors and diagnosticians of the complex infrastructures organisms is imperative and high-priority. To fulfill this objective, we need techniques and technologies that allow us to see inside the structures, to interpret symptoms with a scalable procedure, and to protect the artifacts.

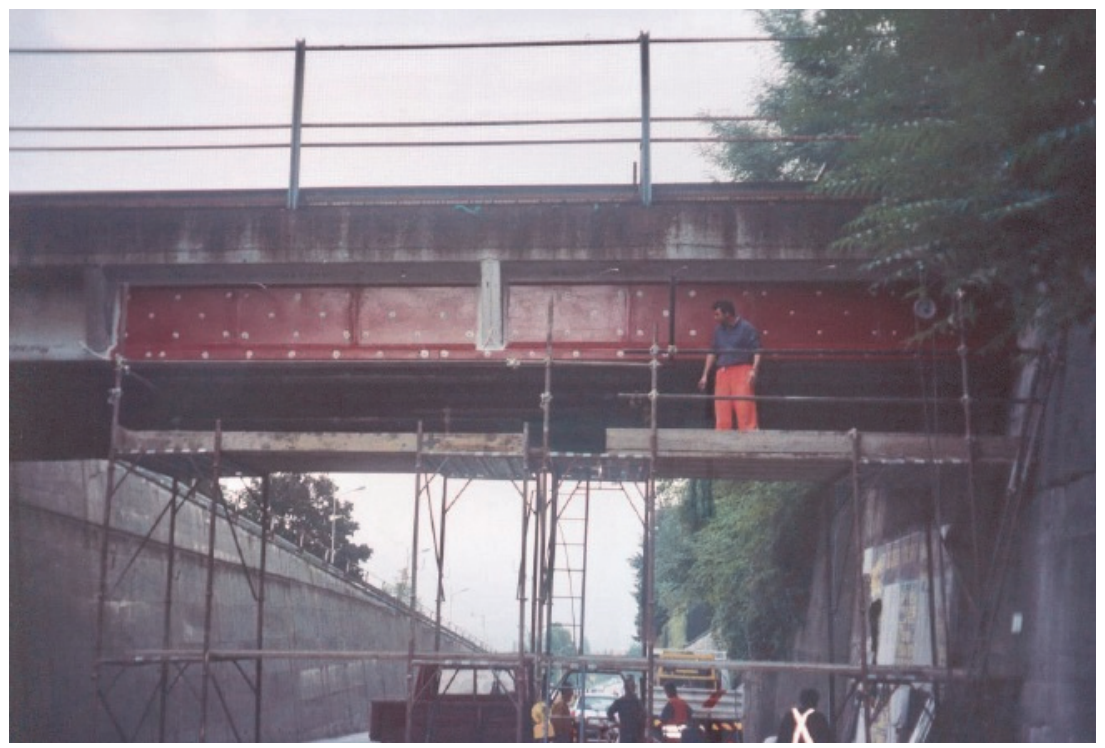

Figure 19: Steel resurfacing for I-beams of an overpass [Copyright: RELUIS].

a)

EMITTER (NOVO-DR)
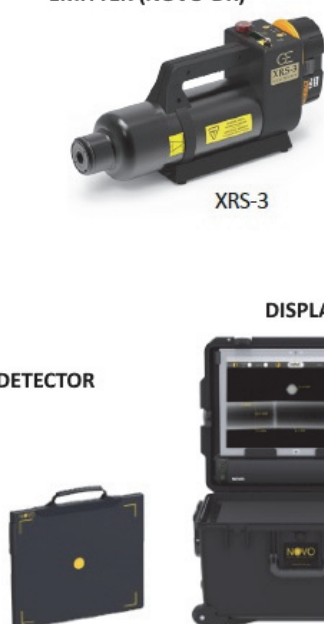
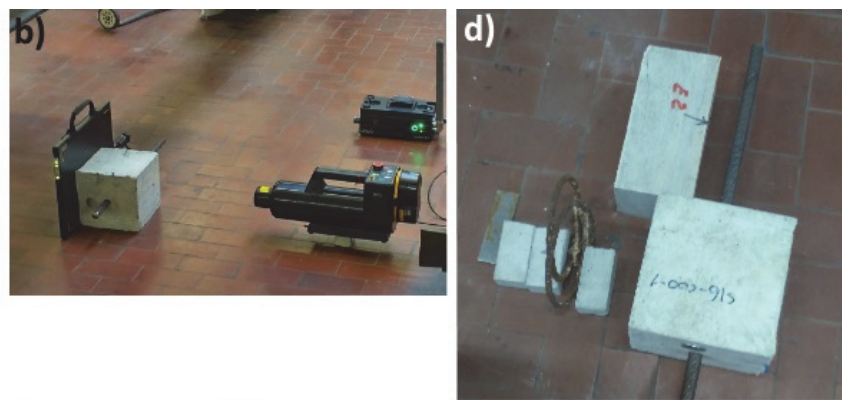

DISPLAY
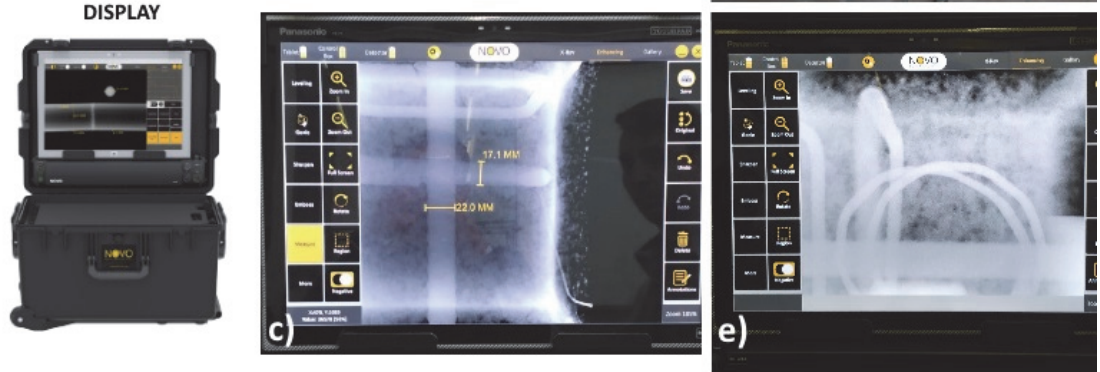

Figure 20: X-Ray device (a) [Copyright: https://www.novo-dr.com/]; scanned image (b) of specimen (c); scanned image (d) of specimen (e).

\section{X-ray inspections}

As has been said, referring the state of a SHM system to a quantitative degree is not possible in the majority of cases. Moreover, precast structures suffer from an intrinsic fragility due to the technology itself. The decay of structural properties is difficult to detect until the ultimate steps of the load capacity curve [5]. To a reduction in cable section, corresponds an increase of stress in the effective area without any significant decrease in global properties. Otherwise, the area reductions observed in the previously illustrated cases were considerable. The collapse of Fossano bridge must have been occurred with a local reduction, in the total cables section, of at least $35 \%$ of the initial one. This means that, a 
system that is able make emerge the damage from an inspection could be very useful in assessing the safety conditions. Moreover, it allows a previous screening for where to install detailed SHM tools and help for their result interpretation. A promising way to pursue is represented by portable Digital Radiography (DR) devices [32]. In contrast to film or Computed Radiography, (DR) uses an X-ray digital image capturing device (Figure 20a). X-rays allow an "under skin" reading of the material, allowing to establish the presence, the position and, with a good approximation, the diameter of the reinforcements, the cables, the strands. Moreover, if the protocol to be used is suitably calibrated, the x-rays allow to detect anomalies such as the presence of voids, the presence of non-coherent materials and segregation effects.

The system is usually composed by an emitter, a real time display and a shield detached detector (Fig. 20(a)). This technology enables to generate immediate and high-quality X-ray images while keeping radiation levels to the minimum. Fig. 20(b) shows the results of an X-Ray test conducted in Politecnico di Torino laboratory Fig. 20(c). The system exhibited a significant power of penetration, completely scanning the 150x150x150 mm concrete cube. Furthermore, the system was able to detect additional reinforcement positioned beyond the cube, then has a great potential also for the inaccessible portion of a structure (Fig. 20(d), Fig. 20(e)). The all system weight less than $200 \mathrm{~kg}$ (the heavier component is the detector, $150 \mathrm{~kg}$ in its largest dimension) and can be easily carried by a robotic-arm installed on a vehicle (Fig. 21). Inspection of I-beams could be carried by a scraped scanning. Of course, this method represents a screening procedure but could be extremely reliable and effective for a preliminary census or fast track assessment.
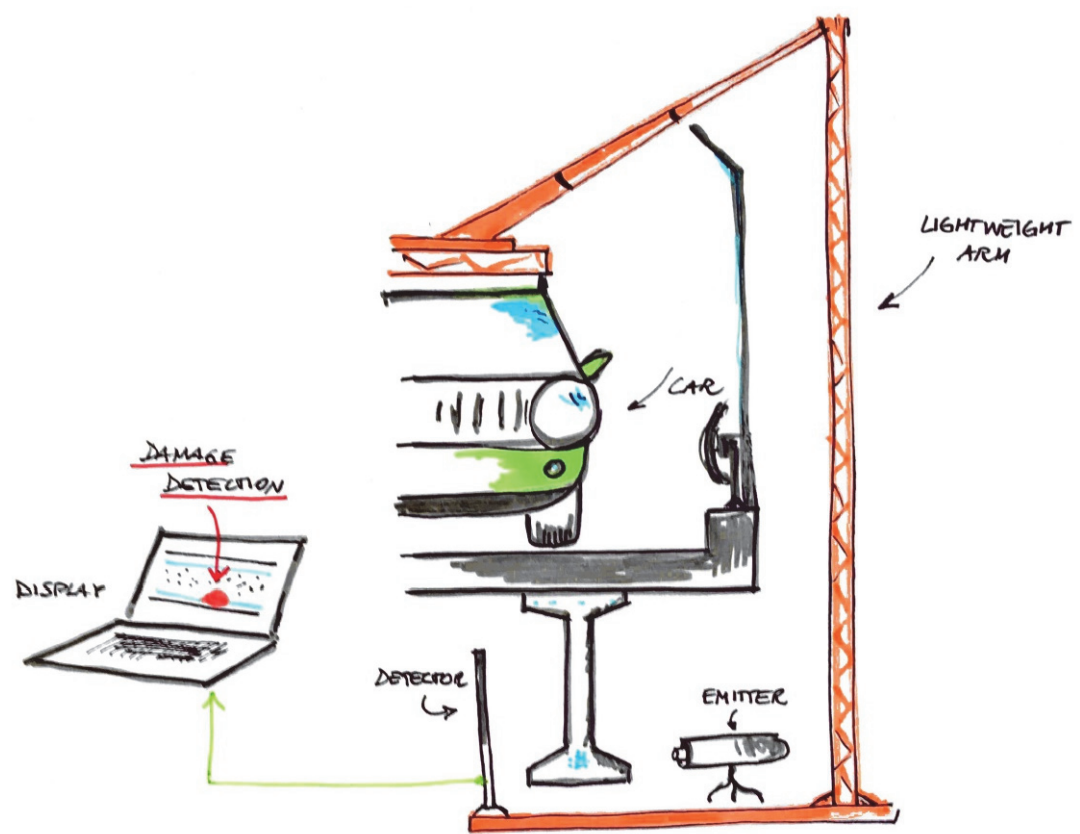

Figure 21: Vehicle screen scanning.

\section{Artificial Intelligence: Computer Vision and Pattern Recognition}

Artificial intelligence (AI) is a definition that groups altogether the techniques in computer science that solve a problem (or a task) by building an algorithm-based (or a series) agent that acts in a certain environment and not by following a series of dictated operations [33]. From 1965, the scenario of AI broadened so vastly that each its subfield could be considered as an independent field of study, as for Machine and Deep Learning (DL), Computer Vision (CV), Soft Computing, Human-inspired Intelligence, and Neural Networks (NN). To exploit the process of an agent to act, the ability of computational platforms to "learn" has to be explored. In general, when a problem is ascribable as a goalfunction for completing the task, we speak of classic Machine Learning. The agent is an algorithm that solves the problem by maximizing its goal completion in the fastest way. Each ameliorative step it is transformed in boundaries for the algorithms series and it is defined learning process. These series are usually neural networks, that operate with different goals in every node (neuron) of the net [34]. The advantages of problem solving with classic AI are mostly (i) the desired task is completed without human intervention and (ii) the system is self-improving. The revolution of big-data changed, and boosted, the practice of AI. If the system is well trained, it could detect, classify, recognize and predict results in particular scenarios, as human brain does in everyday life. In imitating human intelligence and perception, the most advanced field is Vision. The reason is connected to the large similarity between the structure of the human eye and 
today's image capturing devices (camera and video-frames) [35]. The fovea of the retina eye is similar to a digital sensor camera: a cluster of retina cones that like pixels are light sensitive and with three recording channels [36]. Digital images are essentially matrix that contains the color information at each pixel by a $2^{\mathrm{n}}$-bit byte. $\mathrm{n}$ provide the order of the image, for example for $\mathrm{n}=3$, we have 8-bit images with 256 possible colors given by the combination of the three RGB channels. This means that digital image processing is nothing more than a multidimensional algebra on matrices. Among the many ways that an image can be processed, it is worth to note, for Civil Engineering applications, the filtering, recognizing and detecting operations. To filter an image, matrices are usually multiplied by filters of the same dimension of the image, which at each pixel computes the value of a certain neighborhood of the original image. It exists filters for smoothing, sharpening, averaging or contrasting. Recognizing and detecting are operations performed by convolution between the original image with a smaller matrix, called mask. The mask contains fixed information for the object to detect or trained information for object to recognize. The training of a diagnostic CV algorithm commonly follows two ways: Feature Extraction or Deep Convolution Neural Network (DCNN) [37]. The former one, uses constrained learning over some target features obtained by image processing (i.e. object detection). Its computational burden results to be scarce, but it requires to select a priori where and what to search for. DCNNs instead look for correlation over two datasets, one of whom is used as ground truth [38]. This means the prior knowledge is related to the meaning of the image and not to the driving variables, which instead remains hidden. When DL is involved, the system develops a sort of intuition in recognizing common features as a function of the state variables (dimension of the problem). This operation takes the name of pattern recognition [39]. It is now clear that a system that can recognize and detect damages from image capturing and another one that extract and classify them as a function of common variables could be very useful for large scale diagnosing. In fact, AI with this framework has been successfully used in human medicine in the last years [40]. Some attempt to use NN for structural automated inspection of steel bridges [41] and for general damage detection [42] has been recently proposed. Preliminary results of $\mathrm{CV}$ and pattern recognition application to the Fossano bypass road are presented. As described above, the Fossano overpass in one of the 108 bridges that puts together the entire Viaduct. This has been built between 1991 and 1997, and apart from the railway overpass and four short ramps, each bridge has the same structural scheme of the collapsed one. After the failure, the viaduct underwent a series of structural investigations: two time-delayed load tests, tomography, dynamic identifications and Georadar scanning. No decisive results have been extracted yet (due to the problems described above), but they produced a lot of data that can be correlated by pattern recognition to visual inspections. Chemical inspections have evidenced that two particular superficial stains could be related to internal conditions of the prestressing cables.

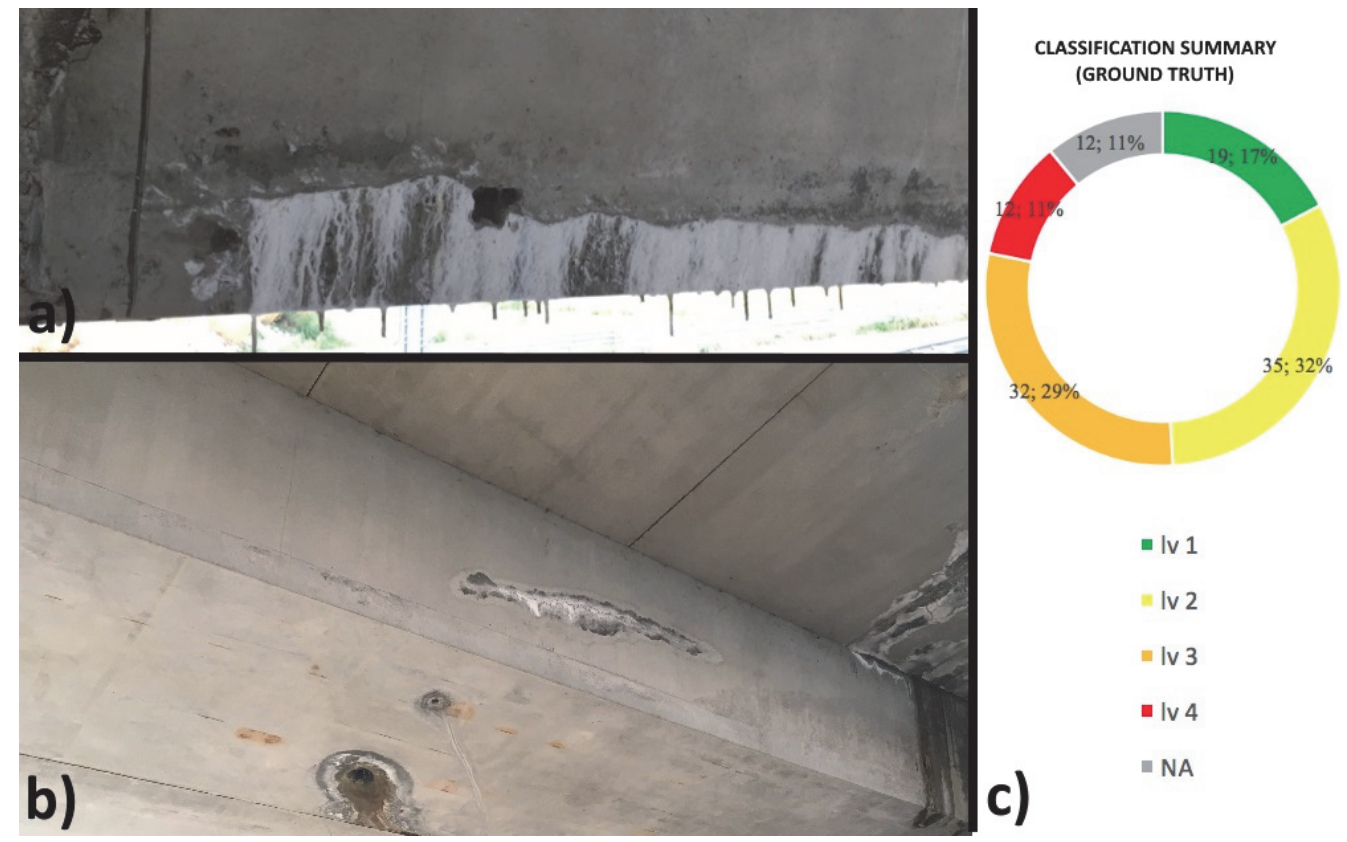

Figure 22: White stains due to grout drainage (a); red-brown stains due to corrosion (b); results from classification (c).

The spot in Fig. 22(a) exhibits a with a pale color and a layered aspect. This stain testifies a drainage of the grout by water seepage inside the cables. This obviously implicates inadequate water protection but also suggest that the cables lie in 
bonded condition. At the contrary, red-brow stains (Fig. 22(a)) suggest unprotected cables and rust transport by continuous water gradient. This latter condition represents of course the worst scenario, with maximum damage and lower robustness. The presence of this particular damage has been catalogued as Lv.4 (red) for the entire bridge. Extended and joint-diffused white stains have been catalogued as Lv.3 (orange), while local or isolated as Lv.2 (yellow). Lastly, a clear external surface of the bridge deck has been assigned to a Lv.1 degree of damage (green). After the first photographic campaign, an image classification (labeling) has been carried out manually by experts. Results of this classification are shown in Fig. 22c. These results have been used as ground truth for the building of the image layer of a DCNN CV detector Fig. 23(a). The set has been splitted in 65\%-35\% for training and validation. Before training, each picture has been filtered for red-contrast enhancement. A random set of 200 images from Kaggle has been used as false test. Training lasted 21 hours on a 2014 MacBook Pro. DCNN has been implemented with Pytorch and Anaconda 3.5.2.0. Other two layers have been implemented in the net, one based on the results of the load test and one on the dynamic properties of the bridge, both computed by a FEM tuned model Fig. 23(b). To date, other two photographic campaigns (tablet-based) have been carried out by A.N.A.S. technicians, and Fig. 24(a) shows the results of the application of the DCNN on the bridge n. 48. The system correctly spotted a red stain and classified the bridge as a Lv.3. Analogously, for bridge n. 52 (Fig. 24(b)), a Lv.4 classification has been successfully matched. Regarding instead span $\mathrm{n}$. 85, classified Lv.3 manually, the DCNN detected a Lv.2. damage degree Fig. 25(a).

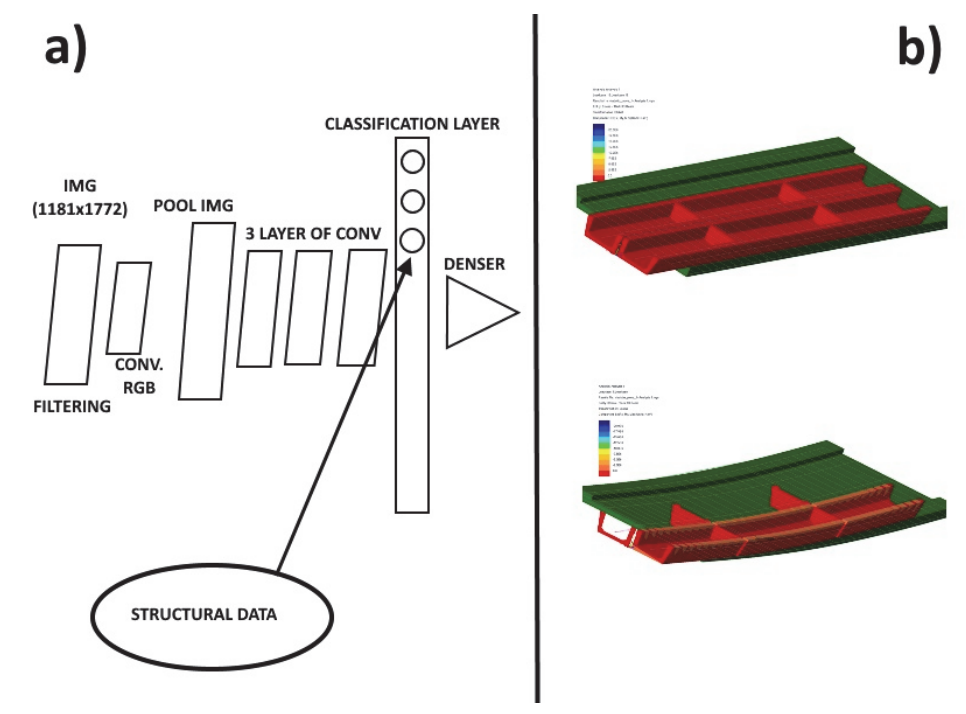

Figure 23: DCNN scheme (a); FEM tuned model (b).

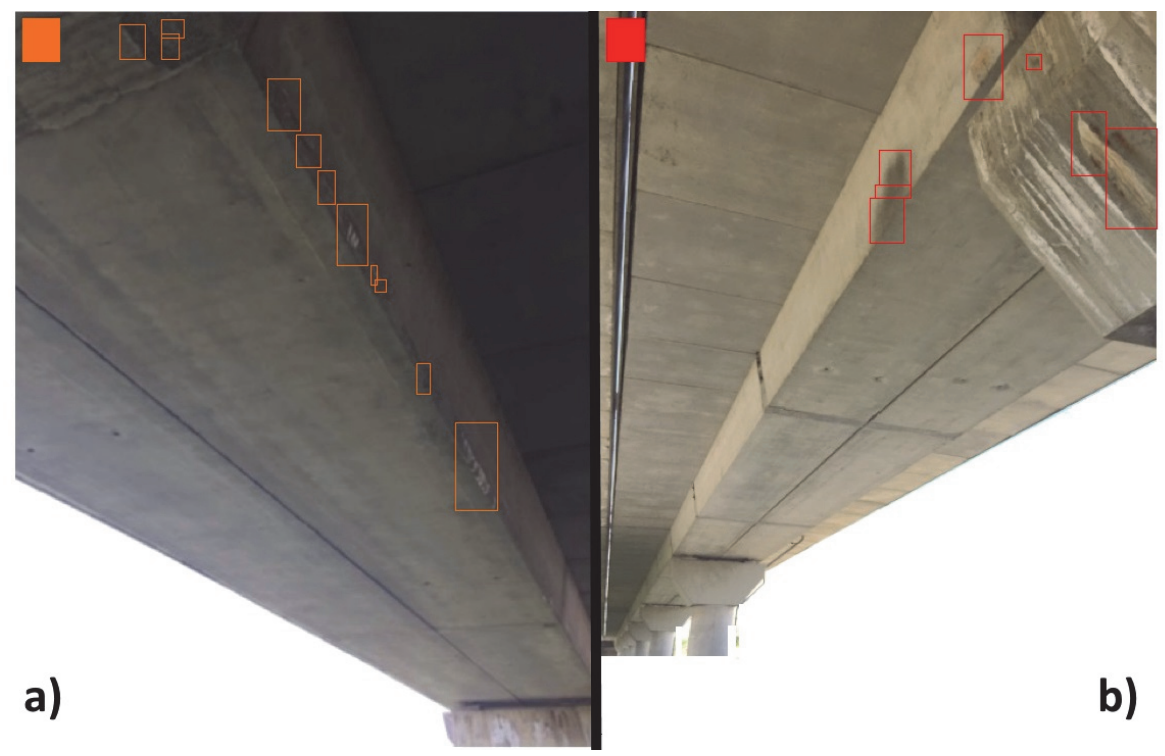

Figure 24: Detection of a Lv.3 damage (a); detection of a Lv.4 damage (b). 
To date, $73 \%$ of accuracy has been encountered, and after the second campaign no evolution from previous damage degree has been noticed. Because of the assembled arrangement, a new set of analyses has been carried out in classifying the damage degree of each precast element (6 for each span). A preliminary result has been shown in Fig. 25(b). To recognize each element, a manual segmentation on the image has been carried out, but as a future goal the system will be trained to autonomously recognize the bridge structural members. In the panorama of large-scale application, an interesting work has been recently published [43]. The pattern recognition is focused on detecting the modal shapes and free vibrations of a bridge by analyzing the huge amount of data stream of smartphones residents that crosses the bridge. In this case, many raw data and an intelligent DL algorithm could capture the desired dynamic features with acceptable accuracy.

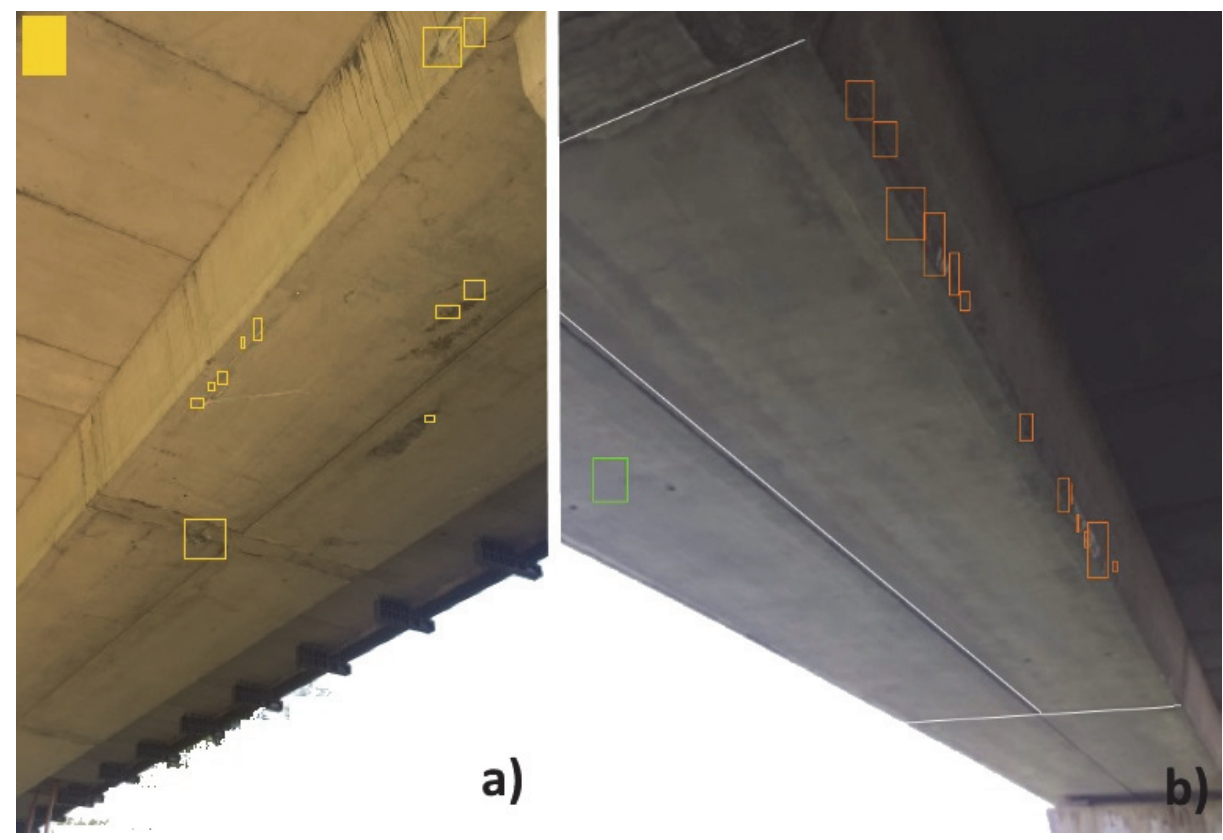

Figure 25: mismatch of damage degree (a); element-scale analysis (b).

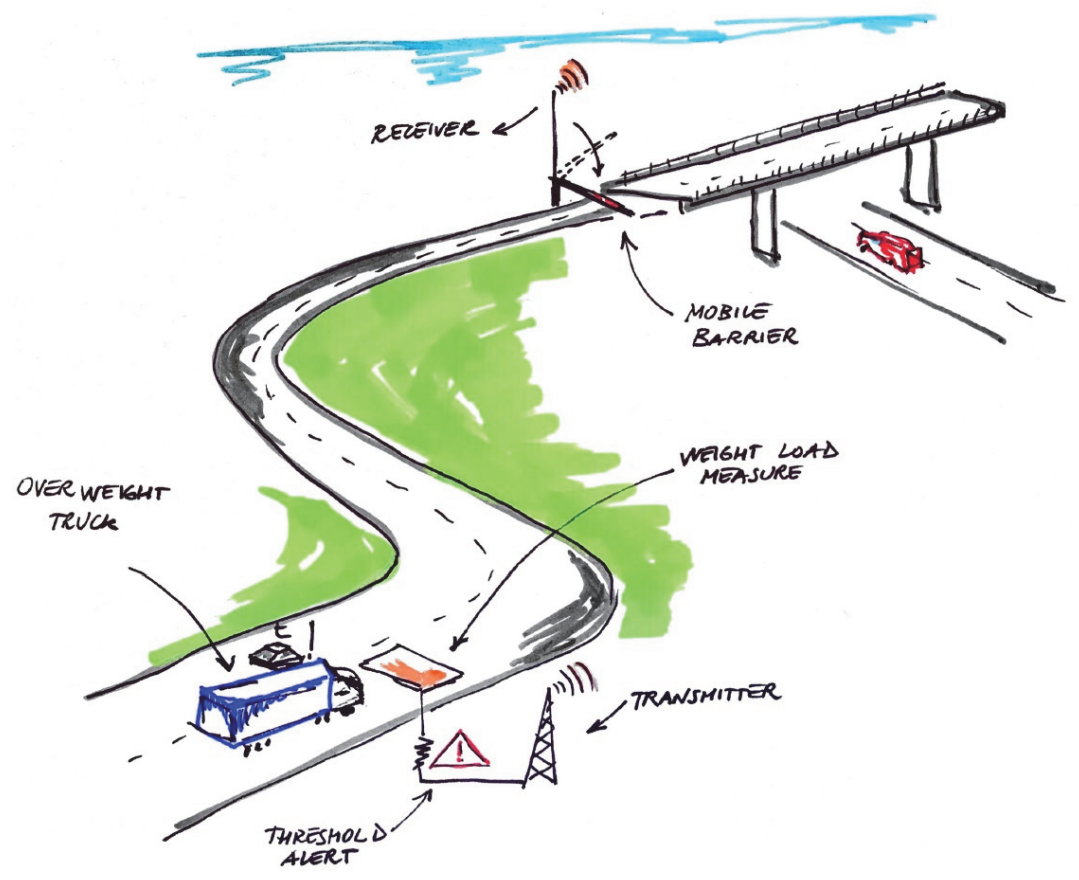

Figure 26: Weight detection systems. 


\section{Load Checking and real-time monitoring}

Collapses as the one of the Annone overpass have demonstrated that a check on the actual traffic loads is essential to assess the safety factor of an existing artifact. In fact, the category of the bridge relies on the possible applied maximum load. In order to do so, a weight-detection system, based on embedded actuators (piezo-actuators or fiber optic coils) in the asphalt, could be applied in a preventive distance before the bridge to cross. The device, like a Velox detector, check the admissible vehicular weight and allow the bridge crossing (Fig. 26) [44]. Otherwise, the truck would be halted by an automated barrier. The system should be tuned for heavy loads, remaining blind for car vehicles or small vans. The entire road infrastructural framework will benefit from the installment of this control system by the following cornerstones:

- exact heavy or exceptional load census that cross the bridge;

- more precise data for fatigue analyses and vibrational maintenance;

- potholes and asphalt management;

- chance to perform detailed model updating, when a permanent SHM or SID is applied, by the knowledge of the actual acting force and relative structural response.

\section{CONCLUSIONS}

$\mathrm{R}$ oad and highways always had a vital importance in the Italian infrastructural system, because of their great ability to penetrate the Italian territory. Moreover, their maintenance can represent together with protection of buildings and industrial plants and restoration of the historical heritage, a great driving force for economic development for the country.

Prestressed concrete structures have often been used in the past for their ease of construction, flexibility of use and, above all, their economic efficiency compared to other design solutions. Unfortunately, however, time and catastrophic events have shown how the prestressed reinforced concrete structures exhibit structural sufferings.

The prestressed concrete structures built during the economic boom have shown some vulnerabilities, with heavy consequences in terms of long-term strength capacity. The causes of the degradation are, unfortunately, quite clear: lack of planning, improper execution of the design and incorrect use of building materials. But what is always little emphasized, is the relationship between the building and its time: knowledge, techniques, materials have evolved exponentially in the last 30 years. The concept of robustness, which in the scientific sector is now a widely used term, can certainly not be associated with structures born over 50 years ago. Durability has been estimated in a completely intuitive way and the behavior of concrete subjected to cyclic loads to fracture it was a completely unknown problem.

Analyzing the recent events in Italy, a rather varied and at the same time worrying "framework" on road infrastructure safety emerges. This framework can be summarized by the following items:

- absence of an adequate degree of structural ductility and strength, mostly linked to the period of construction and/or the employed material;

- maintenance plans not foreseen or not often carried out, which amplify the deficiencies of the structural system and, consequently, the unpredictable behavior of the construction;

- durability problems (above all) related to the choice of the material used;

- monitoring system applied to already degraded constructions that does not premise to fully interpret the state of progress of the degradation itself, in many cases not homogeneous and inefficient. Often the results are unintelligible, illegible or irrelevant to assess security at a certain absolute magnitude;

- the intrinsic vulnerabilities related to the structural technology adopted;

- low retrofit design capacity linked to the "static" nature of the structural design of road infrastructures.

In the imminent future we will have to front the problem of the deteriorated structures management and, above all, of the survey methodologies. This will be crucial because, for the prestressed reinforced concrete structures, there are reduced external evidences of damage and/or deterioration.

\section{ACKNOWLEDGEMENTS}

$\mathrm{T}$

his research was supported by A.N.A.S. S.p.A. throughout the "Bridge Damage Pattern" grant at Politecnico di Torino. The Author are thankful to Eng. Massimo Simonini and Eng. Achille Devitofranceschi for their support and precious insights. We kindly thank Eng. Marco Negri, for access to photographic database and IT supports. 
Lastly, we would like to express our gratitude to Eng. Gianni Armani for his sincere encouragement in pursuing the research project.

\section{REFERENCES}

[1] Di Prisco, M., Colombo, M., Martinelli, P. and Coronelli, D. (2018). The technical causes of the collapse of Annone overpass on SS. 36, in Italian Concrete Days 2018, Lecco, Italy, pp. 1-16.

[2] Bertolini, L., Elsener, B., Pedeferri, P. and Polder, R. (2004). Corrosion of Steel in Concrete, WILEY-VCH Verlag GmbH \& Co. KGaA, Weinheim.

[3] D.M. 14.01.2008, Norme Tecniche per le Costruzioni 2008, pubblicata sulla Gazzetta Ufficiale 04.02.2008.

[4] Mallett, Geoff P. (1994). Repair of concrete bridges. Thomas Telford.

[5] Wolff, M. and Starossek, U. (2008). Robustness assessment of a cable-stayed bridge in 4th International Conference on Bridge Maintenance, Safety, and Management.

[6] Ghosn, M., Moses, F. and Frangopol, D.M. (2010). Redundancy and robustness of highway bridge superstructures and substructures, Structure and Infrastructure Engineering, 6(1-2), pp. 257-278.

[7] Rigacci, R. and Romagnolo, M. (1995). Il risanamento del viadotto Polcevera, Le Strade, 1-2, pp. 9-16.

[8] Gentile, C. and Martinez y Cabrera, F. (1997). Dynamic investigation of a repaired cable-stayed bridge, Earthquake engineering \& structural dynamics, 26(1), pp. 41-59. DOI: https://doi.org/10.1002/(SICI)1096-9845(199701)26:1<41::AID-EQE622>3.0.CO;2-U

[9] Rodado, J. and Manterola, J. (2001). Multi-span cable stayed bridges Iin IABSE Symposium Report 84 12, pp. 25-33.

[10] Malerba, P.G. (2014). Inspecting and repairing old bridges: experiences and lessons, Structure and Infrastructure Engineering, 10(4), pp. 443-470.

[11] Martinez y Cabrera, F. and Pisani, F. (1994). Rehabilitation of stays of the Polcevera Viaduct in Proceedings of the Int. Symp. on Cable Stayed Bridges, pp. 640-665.

[12] Dari, A. (2018) Un piano Marshall per i ponti, per le scuole, per le case...riflessioni dopo la tragedia di Genova, Ingenio.

[13]JCSS, J., (2001). Probabilistic model code. Joint Committee on Structural Safety.

[14] Menduni, E. (1999). L'autostrada del sole (Vol. 12). Il mulino.

[15] Malerba, P.G., (2010). Managing old bridges, in Bridge Maintenance, Safety, Management and Life-Cycle Optimization: Proceedings of the Fifth International IABMAS Conference, Philadelphia, USA, p. 43.

[16] Otsuki, N., Miyazato, S.I. and Yodsudjai, W., Influence of recycled aggregate on interfacial transition zone, strength, chloride penetration and carbonation of concrete. Journal of materials in civil engineering, 15(5), (2003) 443-451.

[17] Collepardi, M., Marcialis, A. and Turriziani, R. (1972). Penetration of chloride ions into cement pastes and concretes, Journal of the American Ceramic Society, 55(10), pp. 534-535.

[18] Gonzalez, J.A., Algaba, J.S. and Andrade, C. (1980). Corrosion of reinforcing bars in carbonated concrete, British Corrosion Journal, 15(3), pp. 135-139.

[19] Šauman, Z., (1971). Carbonization of porous concrete and its main binding components, Cement and Concrete Research, 1(6), pp. 645-662.

[20] Morandi, R. (1979). The long-term behaviour of viaducts subjected to heavy traffic and situated in an aggressive environment: the viaduct on the Polcevera in Genoa, in IABSE reports of the working commission.

[21] Troli, R., Collepardi, S., Collepardi, M. (2018). In merito alla scarsa durabilità nel tempo del viadotto sul Polcevera. Le riflessioni del Prof. Morandi dopo 12 anni dalla costruzione del ponte, Villorba (TV).

[22] Courard, L., Bissonnette, B. and Garbacz, A. (2018). Specification Guidelines for Surface Preparation of Concrete Prior to Repair, in High Tech Concrete: Where Technology and Engineering Meet, pp. 140-147.

[23] Scibilia, N. and Giancontieri, S. (2016). The resistance of prestressed beams of the Akragas bridge (SS 115-AG), Atti Italian Concrete Days, Roma 27-28 Ottobre.

[24] O'Flaherty, F., Van Nguyen, C., Lambert, P., Mangat, P. and Jones, G. (2018). Optimised cathodic protection design for maximum bond performance in reinforced concrete, Materials and Corrosion. DOI: https://doi.org/10.1002/maco.201810116.

[25] Slate, F.O. and Hover, K.C. (1984). Microcracking in concrete, in Fracture mechanics of concrete: Material characterization and testing, pp. 137-159.

[26] Ferro, G. (2006). On dissipated energy density in compression for concrete, Engineering Fracture Mechanics, 73(11) pp. 1510-1530. DOI: https://doi.org/10.1016/j.engfracmech.2006.01.037. 
[27] Dolce, M. and Manfredi, G. (2001). Linee guida per riparazione e rafforzamento di elementi strutturali, tamponature e partizioni, ISBN-10: 8889972297

[28] Ding, Y.L., Ren, P., Zhao, H.W. and Miao, C.Q. (2018). Structural health monitoring of a high-speed railway bridge: five years review and lessons learned. Smart Structures and Systems, 21(5), pp. 695-703.

[29] Nasrollahi, A., Deng, W., Ma, Z. and Rizzo, P. (2018). Multimodal structural health monitoring based on active and passive sensing, Structural Health Monitoring, 17(2), pp. 395-409.

[30] Hasni, H., Jiao, P., Alavi, A.H., Lajnef, N. and Masri, S.F. (2018). Structural health monitoring of steel frames using a network of self-powered strain and acceleration sensors: A numerical study, Automation in Construction, 85, pp.344357.

[31] Ratti, C., and Claudel, M. (2016). The city of tomorrow: Sensors, networks, hackers, and the future of urban life. Yale University Press.

[32] Yaffe, M.J. and Rowlands, J.A. (1997). X-ray detectors for digital radiography. Physics in Medicine \& Biology, 42(1). DOI: https://doi.org/10.1088/0031-9155/42/1/001.

[33] Russell, S.J. and Norvig, P., (2016). Artificial intelligence: a modern approach. Malaysia; Pearson Education Limited.

[34] Hippert, H.S., Pedreira, C.E. and Souza, (2001). Neural networks for short-term load forecasting: A review and evaluation, IEEE Transactions on power systems, 16(1), pp. 44-55.

[35] Prince, S.J., (2012). Computer vision: models, learning, and inference. Cambridge University Press.

[36] Petrou, M. and Petrou, C. (2010). Image processing: the fundamentals. John Wiley \& Sons.

[37] Ngiam, J., Khosla, A., Kim, M., Nam, J., Lee, H. and Ng, A.Y. (2011). Multimodal deep learning, in Proceedings of the 28th international conference on machine learning (ICML-11), pp. 689-696.

[38] Hoo-Chang, S., Roth, H.R., Gao, M., Lu, L., Xu, Z., Nogues, I., Yao, J., Mollura, D. and Summers, R.M. (2016). Deep convolutional neural networks for computer-aided detection: $\mathrm{CNN}$ architectures, dataset characteristics and transfer learning, IEEE transactions on medical imaging, 35(5), pp. 1285.

[39] Anzai, Y. (2012). Pattern recognition and machine learning. Elsevier.

[40] Buch, V.H., Ahmed, I. and Maruthappu, M. (2018). Artificial intelligence in medicine: current trends and future possibilities, Br J Gen Pract, 68(668), pp. 143-144.

[41] Cha, Y.J., Choi, W., Suh, G., Mahmoudkhani, S. and Büyüköztürk, O. (2018). Autonomous structural visual inspection using region based deep learning for detecting multiple damage types, Computer Aided Civil and Infrastructure Engineering, 33(9), pp. 731-747. DOI: https://doi.org/10.1111/mice.12334.

[42] Hoskere, V., Narazaki, Y., Hoang, T. and Spencer Jr, B. (2018). Vision-based Structural Inspection using Multiscale Deep Convolutional Neural Networks. arXiv preprint arXiv:1805.01055.

[43] Matarazzo, T., Vazifeh, M., Pakzad, S., Santi, P. and Ratti, C., (2017). Smartphone data streams for bridge health monitoring, Procedia engineering, 199, pp. 966-971. DOI: https://doi.org/10.1016/j.proeng.2017.09.203.

[44] Bajwa, R., Rajagopal, R., Varaiya, P. and Kavaler, R. (2011). In-pavement wireless sensor network for vehicle classification, In: Information Processing in Sensor Networks (IPSN), IEEE. 